\title{
Direct numerical simulation of $n$-heptane/air auto-ignition with thermal and charge stratifica- tions under partially-premixed charge compression ignition (PCCI) engine related conditions
}

\author{
F. Zhang ${ }^{\mathrm{a}}$, H.F. Liu ${ }^{\mathrm{a}}$, J. Yu ${ }^{\mathrm{b}}$, M.Yao ${ }^{\mathrm{a}}$ \\ a, State Key Laboratory of Engines, Tianjin University, Tianjin, P.R.China \\ b, College of Aerospace Science and Engineering, National University of Defense Technology, \\ Changsha, P.R.China \\ *Corresponding author: Yao Mingfa, State Key Laboratory of Engines, Tianjin University, 300072. \\ y_mingfa@tju.edu.cn
}

\begin{abstract}
Two-dimensional direct numerical simulations (2D DNS) are used to study auto-ignition of nheptane/air mixture with charge and temperature stratifications under elevated pressure and temperature conditions relevant to PCCI (Partially-premixed Charge Compression Ignition) engines. Detailed species transport and a skeletal n-heptane chemical kinetics mechanism are employed; the effect of compression/expansion due to piston motion is also taking into account. The result shows that charge and temperature stratifications have an important impact on the ignition delay and the spatial structure of the reaction zones regardless the initial mean temperature $\left(T_{0}\right)$ is within or outside the negative temperature coefficient (NTC) regime. The second-stage ignition delay time decreases as charge stratification increases but it increases with increasing temperature stratification. Larger charge stratification can spread out heat release due to the high sensitivity of ignition delay time to the equivalence ratio $(\varphi)$ and the temperature gradient. Furthermore, stronger turbulence can homogenize mixture fluctuations, but the ignition delay time is similar as that in weak turbulence case because the species diffusion rate is rather weak compared with chemical reaction rate. A series of 1-D simulations are carried out under different $T_{0}$ and $T-\varphi$ correlations to investigate their effect on the combustion process.
\end{abstract}

Keywords: auto-ignition; direct numerical simulation; charge and thermal stratifications; n-heptane; PCCI engines 


\section{Introduction}

Homogeneous charge compression ignition (HCCI) engine is an advanced low temperature combustion engine due to its low level emissions of NOx and particular matter and its high efficiency. Ideally, the lean perfectly premixed charge in HCCI engines is homogeneously auto-ignited by compression; however, there are still several challenges for the application of HCCI engines in commercial vehicles, such as: misfire at low load and high pressure rise rate (PRR), even damage of engines, at high load [1]-[3]. These challenges are due to that the onset of combustion in HCCI is primarily controlled by chemical kinetics of the fuel-air mixture such that it is very sensitive to pressure, temperature and operating load conditions [4]-[6]. One of the promising approaches to circumvent the issue is partially-premixed charge compression ignition (PCCI), which utilizes temperature and charge stratifications [7]-[9].

In HCCI engines, thermal and charge stratifications cannot be avoided due to EGR (end gas recirculation) from the previous engine cycle and the intrinsic flow motion of the charge and heat transfer. The charge stratification in PCCI engine is however different from that in HCCI engines. The charge stratification in PCCI engines is much greater than that in HCCI engines and it is typically generated by the later injection of the fuel. Several experimental studies in HCCI engines have shown that thermal stratifications play an important role in smoothing PRR under high load conditions[10]-[13]. Optical engine results showed that first ignition site occurs in hotter mixtures with random distribution and then propagates to the colder mixtures due to the temperature gradient between the burnt and the un-burnt regions[10]-[13]. However, with thermal stratification only one cannot optimize HCCI combustion properly since the combustion phasing is difficult to control. Furthermore, it is difficult to control and optimize the thermal stratification in engines. The charge stratification in PCCI engines is relatively easier to achieve. Advanced control strategies can be used, e.g., later intake valve closing, multi-injections and narrow-angle injector [14]-[19]. For example, one can use an early-injection to form a homogeneous lean charge, and then a late-injection near the top-dead-center (TDC) to form stratified fuel-rich charge. Previous studies have shown that the 
charge stratification can extend the engine operating range to both low and high load with high efficiency and low emissions[14]-[21].

Numerous experimental observations indicate the importance of charge and thermal stratifications; however, the fundamental physics and chemical processes in PCCI engines are still not well understood. Direct numerical simulation (DNS) is a viable approach to elucidate the mechanism of ignition and the subsequent detailed turbulent combustion phenomena. Two-dimensional (2-D) DNS has been used to study ignition of hydrogen [22][23], DME [24][25], n-heptane [26][27][28] and isooctane [29] combustion in a constant volume relevant to HCCI engine conditions. A general conclusion is that thermal stratification can reduce PRR but the reduction level depends on the initial temperature, and the combustion process is highly sensitive to initial temperature fluctuations 2-D DNS has been used to study the effects of charge stratification [30]. Both positive and negative temperature-charge $(\mathrm{T}-\varphi)$ correlations were investigated in a hydrogen auto-ignition process. A positive T- $\varphi$ means that the high temperature regions have high fuel-air equivalence ratios, while the negative T- $\varphi$ is the opposite. The results revealed that positive $T-\varphi$ correlation shortens the ignition delay whereas combustion duration is longer. For negative T- $\varphi$ correlation, the ignition mode is similar to HCCI combustion. A further study on a lean n-heptane/air mixture with temperature and charge stratifications shows that with a suitable $\mathrm{T}-\varphi$ correlation one can prevent the excessive PRR and control the ignition timing [31]. With higher initial temperature stratification, the contribution of flame propagation to the total heat release is higher.

Both experiments and numerical simulations have shown that fuel properties have a large effect on the onset of ignition and the subsequent combustion process in PCCI engines [31]-[35]. For example, the transition from auto-ignition dominant regime to flame propagation dominant regime depends on the fuels in PCCI engines [26]. Using two-stage ignition fuel n-heptane, it can be found that initial mean temperature $\left(\mathrm{T}_{0}\right)$ and temperature fluctuation $\left(\mathrm{T}^{\prime}\right)$ have a significant influence on the spatial reaction zone structures. If $\mathrm{T}_{0}$ is within the NTC region, the molecular diffusion effect is rather minor, which is different from the single-stage ignition fuel [25][26][29][31]. Meantime, the 
two-stage ignition fuel is sensitive to local equivalence ratio distribution such that the engine load can be extended to higher, while the ignition timing is relatively insensitive to the local equivalence ratio, which renders charge stratification of a single-stage fuel to be less effective for creating a staged combustion event [32][34].

PCCI combustion of a two-stage ignition fuel, n-heptane, is studied here using 2D DNS to investigate how the thermal and charge stratification affect the onset of ignition and the subsequent flame development. A skeletal PRF chemical mechanism including 33 species and 38 reactions [36] was used. The studies are focused on medium load conditions of PCCI engines. The effects of turbulence and compression/expansion due to piston motion are considered. In addition, 1-D simulations are performed for parametric studies to elucidate the effect of initial mean temperature (inside and outside of the NTC regime) and T- $\varphi$ correlations (positive, negative and uncorrelated) on the onset of the first ignition site and the reaction front propagation.

\section{Numerical methods}

The turbulent reactive flows in PCCI engines can be described using the continuity equation, the Navier-Stokes equations, the species and energy transport equations, and the Equation of State, see Eqs. (1)-(5). These governing equations are solved using a high order numerical method [37]. Owing to the relatively low flow velocity, low Mach number assumption is adopted here. The body force and the thermal radiation are neglected due to their relative low importance. The time integration is performed using the second-order Strang splitting method [38], in which the chemical reaction rate is integrated in between two half diffusion and convection time steps. The hydrodynamic pressure is obtained from solution of a variable-coefficient Poisson equation derived from the momentum equations and the continuity equation. This equation is solved with an efficient Multi-grid method to accelerate the convergence. Second order Runge-Kutta combined with Adam-Bashforth (AB2) scheme is used for the temporal evolution. All spatial terms are discretized using a 6th-order central differential scheme except the convective terms in energy and species transport equations, which are solved using a 5th order WENO scheme to avoid numerical wiggles that can lead to unphysical solution. 
The governing equations together with the equation of state are written in the Cartesian coordinates as follows:

$$
\begin{aligned}
& \frac{\partial \rho}{\partial t}+\frac{\partial}{\partial x_{j}}\left(\rho u_{j}\right)=\psi_{\rho} \\
& \frac{\partial \rho u_{i}}{\partial t}+\frac{\partial}{\partial x_{j}}\left(\rho u_{i} u_{j}\right)=-\frac{\partial p}{\partial x_{i}}+\frac{\partial}{\partial x_{j}}\left(\mu\left(\frac{\partial u_{i}}{\partial x_{j}}+\frac{\partial u_{j}}{\partial x_{i}}\right)-\frac{2}{3} \mu \frac{\partial u_{k}}{\partial x_{k}} \delta_{i, j}\right)+\psi_{\rho} u_{i} \\
& \frac{\partial \rho Y_{\alpha}}{\partial t}+\frac{\partial}{\partial x_{j}}\left(\rho Y_{\alpha} u_{j}\right)=\frac{\partial}{\partial x_{j}}\left(-\rho V_{\alpha, i} Y_{\alpha}\right)+\dot{\omega}_{\alpha}+\psi_{\rho} Y_{\alpha} \\
& \frac{\partial \rho h}{\partial t}+\frac{\partial}{\partial x_{j}}\left(\rho h u_{j}\right)=\frac{\partial P}{\partial t}+\frac{\partial}{\partial x_{j}}\left(\lambda \frac{\partial T}{\partial x_{j}}\right)-\frac{\partial}{\partial x_{j}}\left(\rho \sum_{\alpha=1}^{N_{s p}} h_{\alpha} V_{\alpha, j} Y_{\alpha}\right)-\sum_{\alpha=1}^{N_{s p}} h_{\alpha} \dot{\omega}_{\alpha}+\psi_{\rho} h \\
& P=\rho R_{u} T \sum_{\alpha=1}^{N_{s p}} \frac{Y_{\alpha}}{W_{\alpha}}
\end{aligned}
$$

In the above equations $\rho, u_{\mathrm{i}}, T$ and $h$ are density, velocity, temperature and specific enthalpy, respectively. $R_{\mathrm{u}}$ is the university gas constant. $W_{\alpha}$ is the molecular weight of species $\alpha, N_{\mathrm{sp}}$ is the total number of species within the system. $\psi_{\rho}, \psi_{\mathrm{ui}}, \psi_{\alpha}$ and $\psi_{\mathrm{T}}$ are the corresponding source terms due to compression. The compression/expansion effect due to piston motion in a real engine is taken into account by adding a spatially uniform source term to the corresponding mass, momentum and energy equations. This strategy may be considered as modeling the gas phase in a liquid-gas system with vaporization of spatially-uniformed small liquid droplet into gas while neglecting the liquid-gas interactions. Note that when these equations are discretized in a non-conservative form, the source term would not appear explicitly. Therefore, only the source term in the continuity equation needs to be solved, which is expressed after the manipulation as $\psi_{\rho}=\gamma \rho_{0}\left(V_{0} / V^{2}\right)(d V / d t)$, where $V$ is the engine cylinder volume, which is a function of the engine speed and configuration such as stroke length, rod length, piston depth and so on. Subscript 0 represent a reference condition, e.g. initial condition. $\gamma$ is the ratio of specific heats. More details about the numerical method can be found in references [39][40]. 


\section{Problem definition and initial conditions}

The computational domain is a square with a side of $1.2 \mathrm{~mm}$. A uniform grid of $512 \times 512$ is used resulting in a resolution of $2.3 \mu \mathrm{m}$, which is fine enough to resolve the Kolmogorov scales for all the cases. Experiments show that the integral length scale in HCCI engines normally is larger than $2 \mathrm{~mm}$ [41], and a typical DNS study should contain 3-4 energetic length scales. Yoo et al. [29], Bansal et al. [30], Pera et al. [42] used a 2D domain with a size of 3-4 mm, however, the current paper focuses on an intermediate engine load in PCCI engine conditions instead of the low load conditions studied in Refs. [29] and [30], where the equivalence ratio ranges from 0.1 to 0.3 . Here, a relatively higher equivalence ratio of 0.6 is considered and a thinner flame thickness is therefore expected. Due to the limited computational resources, a relatively small domain is chosen. With 4 integral length scales incorporated in the domain, the allowable integral length is thus relatively small. The boundary conditions are periodic. The initial homogeneous isotropic turbulence is prescribed according to PassotPouquet turbulent kinetic energy spectrum [43], which is the same as in the work of Chen et al. [23], Yoo et al. [44], and Mittal et al. [45]. The initial turbulence field is generated using the method described in Ref. [46]. Correspondingly, the initial random thermal and charge stratifications are imposed on the mean temperature and mean equivalence ratio fields. For comparison, a high Reynolds number spectrum is also examined in the next section. The temperature and charge fields are uncorrelated. It is well recognized that turbulence is intrinsically three dimensional and hence, twodimensional turbulence lacks the effect of vortex stretching. However, it has been shown that 2-D turbulence and auto-ignition interaction is fairly similar to that of $3 \mathrm{D}$ process due to the short time scale in PCCI/HCCI engine related conditions. All of the following 2-D cases are computed on TianHe-1(A) system. Each case runs using $642.3 \mathrm{GHz}$ Intel Xeon processors and each case took 24 hours (1536 CPU hours).

Table 1 lists five cases and initial conditions. In all cases the mean initial temperature is $850 \mathrm{~K}$, the mean equivalence ratio $(\varphi)$ is 0.6 and the initial thermodynamic pressure is 40 bar. The initial turbulence intensity $\left(\mathrm{u}^{\prime}\right)$ is $0.2 \mathrm{~m} / \mathrm{s}$ and $2 \mathrm{~m} / \mathrm{s}$, the charge stratification (the root-mean-sqaure (rms) of fluctuations, $\varphi^{\prime}$ ) is 0.05 and 0.3 , the temperature stratification (the rms of temperature fluctuations, $T^{\prime}$ ) 
is $15 \mathrm{~K}$, the corresponding Reynolds number $(\mathrm{Re})$ based on the turbulent integral scale varies from 73 to 730 and Kolmogorov length scale ranges from $3.2 \mu \mathrm{m}$ or $12.3 \mu \mathrm{m}$. The thermal stratification, i.e. the ratio of $T^{\prime} / T=0.0176$ is much smaller than the charge stratification, $\varphi^{\prime} / \varphi=0.5$. In all the cases, the number of integral length scale $\left(L / l_{0}\right)$ is set to be 4 , where $L$ is the computational domain length and $l_{0}$ is the integral length scale.

\section{Results}

\subsection{Ignition process in homogeneous mixtures}

Prior to examining the two-dimensional DNS cases, the ignition process in zero-dimensional (0-D) homogeneous n-heptane/air mixture is simulated using CHEMKIN II under pressure of 40 bar, $\varphi$ of 0.6 and different initial temperatures. Figure 1a shows the ignition delay time $\left(\tau_{0}\right)$, where $\tau_{0}$ is defined as the time at which the PRR reaches its maximum. $\tau_{0}$ indicates the onset of the second stage ignition. According to the study of Curran et al. on n-heptane oxidation [47] $\tau_{1}$ is the time at which low temperature heat release (LTHR) takes place, which is accompanied with heptane isomerization and KETO formation and $\tau_{2}$ refers to the time that high temperature heat release (HTHR) occurs. A negative temperature coefficient (NTC) range is shown in Fig. 1a, from $825 \mathrm{~K}$ to $943 \mathrm{~K}$, during which a higher temperature leads to a longer ignition delay time. In the 2D DNS the initial temperature ranges from $850 \mathrm{~K}$ to $1050 \mathrm{~K}$, which covers the NTC regime and the high temperature single stage ignition regime.

Figure $1 \mathrm{~b}$ shows the first- and the second-stage ignition delay time of n-heptane/air under initial pressure of 40 bar, initial temperature of $850 \mathrm{~K}$ and different equivalence ratios computed using the DNS code under zero-dimensional homogeneous mixture conditions. From the figure, it is concluded:

- When $\mathrm{T}_{0}(850 \mathrm{~K})$ is within the NTC region, both $\tau_{1}$ and $\tau_{2}$ decrease as $\varphi$ increases and there is LTHR in a wide range of equivalence ratios. In addition, $\tau_{2}$ decreases with an increase of $\varphi$ at first and then it remains nearly constant with further increasing $\varphi$. As shown in the figure, $\tau_{1}$ is $0.15 \mathrm{~ms}$ and $\tau_{2}$ is $0.5 \mathrm{~ms}$ for $\varphi=0.6$. 
- At the same temperature, larger charge stratification tends to ignite earlier. With an increase of equivalence ratio, the discrepancy between the first and the second ignition delay time tends to be smaller. As expected, when $\mathrm{T}_{0}$ is outside the $\mathrm{NTC}$ regime, two-stage heat release cannot be observed, see Fig. $2 b$.

Accordingly, Fig. 2a shows temperatures evolution as a function of time at various initial temperatures for the 0-D cases. N-heptane/air mixture demonstrates two-stage ignition characteristics for $\mathrm{T}_{0}<900 \mathrm{~K}$ : after an initial induction the temperature increases a little due to low temperature heat release, which is then followed by another induction period, until eventually the mixture goes to thermal runaway corresponding to the high temperature kinetics pathways. It can also be seen that the first-stage ignition is advanced with higher initial temperature, indicating that low temperature combustion occurs earlier. From $775 \mathrm{~K}$ to $825 \mathrm{~K}$, the main ignition advances, however, from $825 \mathrm{~K}$ to $950 \mathrm{~K}$, the main ignition is retarded. At $\mathrm{T}_{0}=950 \mathrm{~K}$, the first-stage ignition disappears, which indicates the return to conventional high-temperature pathways and single stage ignition occurs, and $\mathrm{T}_{0}=$ $1050 \mathrm{~K}$ again ignites earlier than $\mathrm{T}_{0}=950 \mathrm{~K}$. These observations are very similar to previous discussion of n-heptane kinetics, showing that two-stage ignition does not exist for $\mathrm{T}_{0}>940 \mathrm{~K}$ and the range between $\mathrm{T}_{0}=850 \mathrm{~K}$ and $934 \mathrm{~K}$ is within the NTC regime. Figure $2 \mathrm{~b}$ presents ignition delay time as a function of equivalence ratio for $\mathrm{T}_{0}=1050 \mathrm{~K}[44][48]$. As expected, for the higher initial mean temperature with $\mathrm{T}_{0}=1050 \mathrm{~K}$, the first-stage ignition is negligible and hence, $\tau_{0}$ decreases with increasing equivalence ratio. The shortest ignition delay time is found around $\varphi=4$. The trend with regard to both $\tau_{1}$ and $\tau_{2}$, and also the NTC range is very similar to the reduced n-heptane mechanism $[44][48]$.

\subsection{Two-dimensional non-homogenous cases}

First, low and high Reynolds number energy spectra are plotted as a function of wavenumber in Fig. $3 a$, represented by $E_{1}$ and $E_{2}$, respectively. The initial velocity spectrum prescribed is the PassotPouquet spectrum denoted by $\mathrm{E}_{1}$ as follows: 
$E_{1}\left(k ; u, I_{0}\right)=\frac{32}{3} \sqrt{\frac{2}{\pi}}\left(\frac{k}{k_{0}}\right)^{4} \exp \left(-2\left(\frac{k}{k_{0}}\right)^{2}\right)$

where $k$ is the wavenumber, $k_{0}=2 \pi / l_{0}$ is the energetic wave number and $l_{0}$ is the integral scale, and $u^{\prime}$ is turbulent intensity. $\mathrm{E}_{2}$ spectrum is a more general one, covering a range of Reynolds number (cf. Pope [49]), which reads:

$$
E(k)=C\left(\frac{u^{3}}{I_{0}}\right)^{2 / 3} k^{-5 / 3}\left(\frac{k L}{\left(K^{2} L^{2}+c_{L}\right)^{1 / 2}}\right)^{5 / 3+p_{0}} \exp \left(-\beta\left(\left(k^{4}\left(I_{0} \operatorname{Re}_{10}^{-2 / 4}\right)^{4}+c_{\eta}^{4}\right)^{1 / 4}-c_{\eta}\right)\right)
$$

where $R e_{10}$ is the Reynolds number based on the integral scale. The constants are set as $\mathrm{C}=1.5, p_{0}=2$, $c_{\mathrm{L}}=6.78, \beta=5.2, c_{\eta}=0.4$. For $\mathrm{E}_{2}$, the corresponding Reynolds number based on integral scale is 100 . It is seen that for $E_{1}$ the energy at low wavenumbers is higher than the counterpart in $E_{2}$, indicating more energy containing in large scales. However, the energy over-prediction at the large scales reaches a more physical stage during decay, therefore E1 spectrum is adopted in the following 2-D DNS cases for consistent with previous researches [23][24][29]-[31][44][45]. In Fig. 3b, the temporal evolution of turbulence intensity for the high and low turbulence cases 1 and 3 is shown. In case 1 , $\mathrm{u}^{\prime}$ decays from $1 \mathrm{~m} / \mathrm{s}$ to $0.75 \mathrm{~m} / \mathrm{s}$ prior to auto-ignition event, while in case 3 , it is $1.42 \mathrm{~m} / \mathrm{s}$ at the onset of ignition which shows a decrease by $30 \%$. Due to the shorter ignition delay time, turbulence decaying plays a minor role on turbulence/chemistry interactions.

To look into the details of the two-stage ignition process, Fig. 4 shows 2-D distribution of heat release (HR), fuel (n-heptane) and several intermediate species, $\mathrm{OH}, \mathrm{HO}_{2}, \mathrm{H}_{2} \mathrm{O}_{2}$, at four time instants $0.089 \mathrm{~ms}, 0.16 \mathrm{~ms}, 0.28 \mathrm{~ms}$ and $0.4 \mathrm{~ms}$ for case 1 . Combustion progresses in the following manner: beyond the first-stage ignition i.e. $0.089 \mathrm{~ms}$, a small amount of $\mathrm{HO}_{2}$ is formed accompanying with some heat randomly distribution in the domain. Subsequently the combustion goes into LTHR stage at $0.16 \mathrm{~ms}$, more heat is released in a thin reaction layer which coincides with $\mathrm{OH}$ and $\mathrm{HO}_{2}$ contour in an annular region due to the presence of charge and thermal stratifications. The thin reaction front disappears at $0.28 \mathrm{~ms}$, and hence the level of $\mathrm{OH}$ and $\mathrm{HR}$ decreases but $\mathrm{H}_{2} \mathrm{O}_{2}$ continues to accumulate. Until $0.4 \mathrm{~ms}$, it turns to HTHR stage where heat is patchy in distribution and $\mathrm{H}_{2} \mathrm{O}_{2}$ is still high 
which will finally decomposes to two $\mathrm{OH}$. Normally, $\mathrm{OH}$ is formed through the decomposition of $\mathrm{H}_{2} \mathrm{O}_{2}$ and the consumption of $\mathrm{OH}$ with fuels releases heat dramatically.

Figure 5a shows temporal evolution of volume-averaged pressure and volume averaged total heat release rate for the various 2-D cases to examine the overall combustion characteristics. Due to $\mathrm{T}$ and $\varphi$ stratifications, $\tau_{1}$ and $\tau_{2}$ are shorter than those in the corresponding homogeneous 0 -D case (cf. Fig. 1b). Furthermore, a larger degree of charge stratification results in a smaller LTHR, lower HTHR peak and also the time for HTHR is advanced as shown in Fig. 5b. The reason is that large $\varphi^{\prime}$ leads to more favorable ignitable sites, and thus the increase of combustion duration. A similar trend is also reported in Ref. [24][31][50] and it was shown [50] that even larger charge gradient can delay ignition delay time due to larger diffusive thermal/radicals transport from the ignition location. On the contrary, increasing temperature stratification, the peak of LTHR is reduced and the HTHR is retarded since $\mathrm{T}_{0}$ is in the NTC region. Note that higher temperature will lead to longer ignition delay time in NTC regime. Comparing case 1 and case 2, it is found that in the two-stage ignition event, the influence of charge stratification is primarily reflected in the second stage of ignition, which is consistent with the conclusion in Ref. [50]. This implies that the first ignition stage with different temperature and charge stratifications ignites spontaneously and the effect of turbulence on the firststage ignition is limited owing to the longer turbulence turn over time $\left(\tau_{\mathrm{t}}=l_{0} / u^{\prime}=1.5 \mathrm{~ms}\right)$ in comparison with the local ignition delay time (which is approximately $\tau_{0}=0.15 \mathrm{~ms}$ ).

The evolution of pressure and heat release rate for the cases with different $\varphi^{\prime}$ and $\mathrm{T}^{\prime}$ is shown using time history of the overall volume-averaged temperature gradient and fluctuation. As shown in Fig. 6, the LTHR tends to homogenize temperature distribution because both $\mathrm{T}^{\prime}$ and $|\nabla T|$ decreases after first-stage ignition in all three cases, Cases 1, 2 and 4. Moreover, it is shown that in case 2 with an increase of $\varphi^{\prime}$, both $T^{\prime}$ and $|\nabla T|$ increase dramatically leading to the advancement of first ignition even though initially temperature stratification in case 2 is smaller than that in case 4 . It is noted also that the ignition delay time is very sensitive to the equivalence ratio, see Fig. $1 \mathrm{~b}$. 
For better understanding of the characteristics of important species, Fig. 7 shows temporal evolution of $n$-heptane and major species in case 2 ( $T_{0}$ inside the NTC regime), and case $5\left(\mathrm{~T}_{0}\right.$ outside the NTC regime). For Case 2, at $0.1 \mathrm{~ms}$ n-heptane has already shown a significant decrease, Fig. 7a. According to Ref. [36][51], the reaction pathway of n-heptane in low temperature combustion starts from $\mathrm{H}$ abstraction and $\mathrm{O}$ addition to form relatively stable ketohydroperoxide and $\mathrm{OH}$. As temperature and pressure increase, KETO decomposes to ethylene $\left(\mathrm{C}_{2} \mathrm{H}_{4}, \mathrm{C}_{3} \mathrm{H}_{6}\right)$ and aldehydes $\left(\mathrm{CH}_{2} \mathrm{O}\right.$, $\mathrm{CH}_{3} \mathrm{CHO}$ ), accompanying with a small amount of heat released, indicating LTHR stage. As a consequence, $\mathrm{C}_{2} \mathrm{H}_{4}, \mathrm{CO}, \mathrm{H}_{2} \mathrm{O}_{2}$ and $\mathrm{CH}_{2} \mathrm{O}$ formed after $0.1 \mathrm{~ms}$. At $0.19 \mathrm{~ms}$, the LTHR stage finishes and $50 \%$ of n-heptane is consumed. When it comes to intermediate temperature, the reaction pathways go to alkyl $\beta$-scission and the overall reaction rate decreases which is the well-known NTC behavior. Since the current temperature is above $950 \mathrm{~K}$, high temperature chemical kinetics becomes active: alkyl decomposition, ethylene oxidation to form formyl $(\mathrm{HCO})$ and formaldehyde $\left(\mathrm{CH}_{2} \mathrm{O}\right)$. At $0.4 \mathrm{~ms}$, the combustion gets into high temperature reactions: n-heptane decomposes to small radicals and further oxidizes to $\mathrm{CO}$, and hence, the peaks of $\mathrm{CO}$ and $\mathrm{HO}_{2}$ are observed. Later, $\mathrm{CO}$ and $\mathrm{OH}$ will oxidize to form $\mathrm{H}_{2} \mathrm{O}$ and $\mathrm{CO}_{2}$ indicating the end of main combustion process and combustion temperature is high. At this time, the piston is at -5 CAD ATDC, implying that it has enough time to oxidize the remaining CO. In contrast, for case $5\left(\mathrm{~T}_{0}=1050 \mathrm{~K}\right)$, the LTHR stage does not appear and n-heptane decomposes to small radicals directly. Thus, a significant amount of intermediate species, i.e. $\mathrm{C}_{2} \mathrm{H}_{4}$, can be seen before the onset of HTHR. In addition, the peak of $\mathrm{CO}$ is lower than that in case 2, see Fig. $7 \mathrm{~b}$, owing to the different thermal pathways.

Previous DNS study demonstrates, for small $\mathrm{T}^{\prime}$, i.e. $15 \mathrm{~K}$, the reaction fronts occur primarily as spontaneous ignition wave, while for large $\mathrm{T}^{\prime}$, i.e. $100 \mathrm{~K}$, the combustion occurs primarily by deflagration [26][44]. The nature of a propagation wave depends on whether the species diffusion and chemical reaction can counterbalance each other. To examine this, Fig. 8 shows the budget terms of reaction rate of $\mathrm{CO}$ and diffusion rate of $\mathrm{CO}$ at LTHR stage $(0.16 \mathrm{~ms})$ and HTHR stage $(0.41 \mathrm{~ms})$ for case 1. The two budget terms are defined as: $\dot{\omega}_{C O}=\frac{d Y_{C O}}{d t}, \dot{D}_{i f f_{-} C O}=\frac{1}{\rho} \frac{\partial}{\partial x_{i}} \rho V_{C O, x} Y_{C O}$, where, $\rho$ 
is density and $V_{\mathrm{co}, \mathrm{x}} Y_{\mathrm{co}}$ is diffusion flux calculated with Fick's law. It is seen that at $0.16 \mathrm{~ms}$, the reaction rate of $\mathrm{CO}$ is positive and larger than the diffusion rate of $\mathrm{CO}$, indicating $\mathrm{CO}$ is forming in an ignition process. On the contrary, at $0.41 \mathrm{~ms}$, the reacting rate of $\mathrm{CO}$ is negative but the absolute value is much larger than the diffusion part, indicating $\mathrm{CO}$ is consuming in an ignition process. In both times the reaction front is ignition controlled. The front propagation speed is much higher than the typical flame speed. Similar results are observed considering other species. Normally, at HTHR stage, $\mathrm{CO}$ can be oxidized to $\mathrm{CO}_{2}$ at a high reaction rate through the following three reactions $\left(\mathrm{CO}+\mathrm{OH}=\mathrm{CO}_{2}+\mathrm{H} ; \mathrm{CO}+\mathrm{O}_{2}=\mathrm{CO}_{2}+\mathrm{O} ; \mathrm{CO}+\mathrm{HO}_{2}=\mathrm{CO}_{2}+\mathrm{OH}\right)$. The first reaction is critical primarily because it is the main conversion path of $\mathrm{CO}$ to $\mathrm{CO}_{2}$ [31]. Furthermore, budget terms of $\mathrm{CO}$ and some other important species (not plotted in the figure) suggest the reaction rate is dominant over the species diffusion rate, such that the combustion process is mainly controlled by chemical kinetics and a spontaneous ignition mode. Note that the turbulence time scale in case 1 is $\tau_{\mathrm{t}}=3.07 \mathrm{~ms}$, almost six times larger than the corresponding homogeneous ignition delay $\left(\tau_{0}=0.6 \mathrm{~ms}\right)$. Therefore, the turbulence eddy time is too long to homogenize mixture fluctuation within the overall combustion timescale, which results in the onset of various ignition kernels, cf. Fig. 4.

On the other hand, the pressure and heat release rate in the high turbulence intensity case (Case 3) are almost the same as that in the low turbulence case (Case 1), even though the turbulence intensity varies ten times (the figure is not present for brevity). Since turbulence time scale $\left(\tau_{\mathrm{t}}=0.307 \mathrm{~ms}\right)$ in case 3 is comparable to the ignition delay time scale $(0.5 \mathrm{~ms}$, see Fig. $1 \mathrm{~b})$, the corresponding ratio of turbulence to homogeneous ignition time, $\tau_{t} / \tau_{0}$, is 0.61 . Thus, there is sufficient time for turbulence to homogenize the charge and thermal fluctuations. Therefore, in the 2-D spatial species distribution it is difficult to identify the thin reaction front and the ignition occurs almost simultaneously in the domain. The results also suggest that the similar ignition delay time in the different turbulent intensity conditions may be due to the high sensitivity of ignition delay time on charge and temperature distribution.

Figure 9 shows temporal evolution of volume-averaged temperature gradient and fluctuation in case 3. Both of them are lower than those in the other three cases, Cases 1, 2 and 4 shown in Fig. 6, 
which indicates that the stronger turbulence plays a role in homogenizing the charge and the temerpature field. This is consistent with the previously results reported in Refs. [23][29][44][52].

\subsection{One dimensional (1-D) non-homogeneous case}

The same DNS code will be used in the corresponding 1-D simulation in the following section to investigate how charge and temperature stratifications affect the auto-ignition of two-stage fuel nheptane. In all the cases, the domain length is $\mathrm{L}=2.5 \mathrm{~mm}$, pressure 40 bar and the mean equivalence ratio is 0.6 . The focus here is on the effect of temperature-equivalence ratio correlations on the igntion process.

It is noted that the distribution of initial temperature within or outside the NTC regime and T- $\varphi$ correlations depend on fuel injection timing, EGR ratio, turbulence mixing and heat conduction between the wall and bulk flow gas. For example, if the fuel is injected very early, $\mathrm{T}$ and $\varphi$ is barely correlated to each other due to turbulence and wall heat conduction. In this case a homogeneous charge but inhomogeneous temperature mixture may be established. If the fuel injection timing is late, $\mathrm{T}$ and $\varphi$ are likely to be negatively correlated owing to the fuel evaporation cooling effect. Therefore, the relations of T and $\varphi$ in 1-D DNS cases A, B and C are prescribed as positive, negative and no correlation, respectively, with $\mathrm{T}^{\prime}=15 \mathrm{~K}, \varphi^{\prime}=0.3$, cf. Figs. 10a, 11a and 12a. From Fig. 10a, it is seen that the mixture in the middle of the domain has the highest temperature $(871 \mathrm{~K})$ and equivalence ratio (1.02). The initial temperature range is $830 \mathrm{~K}-871 \mathrm{~K}$. In case D, the initial mean temperature is $1050 \mathrm{~K}$ and the other conditions are the same as that in case $\mathrm{C}$. In case $\mathrm{E}$, the initial mean temperature is reduced $\left(\mathrm{T}_{0}=788 \mathrm{~K}, \mathrm{~T}^{\prime}=15 \mathrm{~K}\right)$ and a uniform charge is prescribed representing very an early fuel injection case. The initial temperature and equivalence ratio fields are set as sinusoidal profiles.

Figure $10 \mathrm{~b}$ shows the temperature distribution at five instants of time for case A (time sequences: No.1 $=0.0195 \mathrm{~ms}$, No.2=0.137 ms, No.3 $=0.254 \mathrm{~ms}$, No.4=0.41 ms, No.5=0.43 ms). At $0.137 \mathrm{~ms}$, the mixture with both the highest $\mathrm{T}$ and $\varphi$ in the domain center ignites first (comparing with No.1 and 
No.2), indicating the LTHR stage. At $0.41 \mathrm{~ms}$, the HTHR starts as can be seen that the high temperature ignition kernels in the central region develop and then the reacting front propagates to the left and right of the domain. Subsequently, the low temperature region ignites successively and finally all the remaining fuel is consumed. The result shows that, even though two-stage ignition behavior is observed, the negative temperature regime disappears due to the positive $\mathrm{T}-\varphi$ correlation.

Figure $11 \mathrm{~b}$ shows the temperature distribution at five instants of time for case B (time sequences: No. $1=0.013 \mathrm{~ms}$, No. $2=0.224 \mathrm{~ms}$, No. $3=0.393 \mathrm{~ms}$, No. $4=0.406 \mathrm{~ms}$, No. $5=0.471 \mathrm{~ms})$. The results indicate also two-stage ignition but a totally different combustion process compared with case A. After the first-stage ignition at $0.224 \mathrm{~ms}$, the temperature field tends to be homogeneous (only $12 \mathrm{~K}$ difference in space) and the temperature in the center is lower than that in the boundary. Later, the first ignition site occurs in the boundary (comparing with No.2 and No.3) rather than the high temperature region in the center which is a result of both NTC and charge distribution effects. At $0.406 \mathrm{ms,}$ temperature increases quickly at the lower $\mathrm{T}$ and higher $\varphi$ region, forming a characteristic " $U$ " shape. At $0.471 \mathrm{~ms}$, the HTHR stage vanishes. It should be aware that in the middle of the domain $\varphi$ is rather low $(\varphi=0.2)$, such that the combustion temperature is low $(1500 \mathrm{~K})$, leaving an amount of $\mathrm{CO}$ and un-burnt hydrocarbon not oxidized. On the other hand, temperature in the boundary is higher than $2500 \mathrm{~K}$, which produces NOx considerably. These should be avoided in PCCI combustion. Experiments also indicate that too large charge stratification will increase NOx [34].

Figure $12 \mathrm{~b}$ shows temperature distribution at six instants of time for case $\mathrm{C}$ (time sequences: No. $1=0 \mathrm{~ms}$, No.2=0. $342 \mathrm{~ms}$, No.3=0.39 ms, No.4=0.4 ms, No.5=0.41ms, No.6=0.464 ms). Similarly, after first-stage heat release, temperature distribution is fairly homogeneous (0.342 ms). At $0.41 \mathrm{~ms}$, two wave crest at $0.75 \mathrm{~mm}$ and $1.75 \mathrm{~mm}$ emanates quickly, then are the waves at 0.25 $\mathrm{mm}$ and $2.25 \mathrm{~mm}$ and at last in the center $1.25 \mathrm{~mm}$, indicating that increasing $\varphi$ and decreasing $\mathrm{T}$ can induce ignition first but it has a most reactive mixture at the region $\mathrm{T}=857 \mathrm{~K}, \varphi=1.02$ when $\mathrm{T}_{0}$ is within the NTC regime. At $0.464 \mathrm{~ms}$ all the peak temperatures at different wave crest are the same. Correspondingly, Figs. 13 a-c show heat release profile at different times for cases A-C. In case A, 
the reaction front propagates to the left and the right of the domain from time 4 to 5 , while in case B, the blue line emanates from the boundary and propagates to the middle of the domain. Especially in case $\mathrm{C}$, the first reaction front can be observed in time 4 at $0.75 \mathrm{~mm}$ and $1.75 \mathrm{~mm}$, which indicates the most reactive mixture.

Figure 14 shows the temporal evolution of pressure and heat release rate for cases A-C, in which Fig. 14a dispalys the high temperature heat release rate and Fig. 14b the low temperature heat release rate. For case A, LTHR is advanced but HTHR is retarded. The peak of HTHR is increased. On the contrary, LTHR is delayed but the onset of HTHR is earlier for case B. This is due to the initial T- $\varphi$ distribution and the NTC effect. This result is different from that reported in previous study of hydrogen ignition, where it was concluded that positive T- $\varphi$ correlation could shorten ignition delay, whereas negative correlation resulted in volumetric ignition [30]. This difference is due to the twostage ignition of the n-heptane fuel, whereas hydrogen combustion goes through only a single stage ignition.

Case $\mathrm{D}\left(\mathrm{T}_{0}=1050 \mathrm{~K}, \mathrm{~T}^{\prime}=15 \mathrm{~K}\right)$ has an uncorrelated $\mathrm{T}-\varphi$ and $\varphi^{\prime}=0.3$ and the initial temperature is outside of the NTC regime. Only one-stage ignition is observed (the results are shown for brevity). The highest temperature in the center of the domain ignites first and a sequential combustion occurs from the center to the boundaries. Similarly, for case $E\left(T_{0}=781 \mathrm{~K}, \mathrm{~T}^{\prime}=15 \mathrm{~K}\right)$ with uniform charge and the initial temperature also outside of the NTC regime, the combustion process is close to case A (for brevity the result is not shown here). Two-stage ignition in this case is observed: the ignition kernel occurs initially at the hottest region, in the middle of the domain, and then the ignition front approaches the boundary of the domain to consume the remaining fuel. It is also found that the reaction rate of $\mathrm{OH}$ is much larger than the diffusion rate of $\mathrm{OH}$, suggesting a less important effect of species diffusion rate. The same conclusion can be drawn from all 1-D cases, which is consistent with Ref. [25], where it was shown that the molecular diffusion rate for two-stage ignition fuel is very small. 


\section{Conclusions}

This paper reports two-dimensional DNS on the effects of charge and thermal stratifications and initial mean temperatures on the auto-ignition of n-heptane/air mixtures under high temperature and elevated pressure conditions relevant to PCCI engines. Six 2-D DNS cases are performed with $\varphi^{\prime}$ of 0.05 and $0.3, \mathrm{~T}^{\prime}$ of $15 \mathrm{~K}$ and $30 \mathrm{~K}$, $\mathrm{u}^{\prime}$ of 0.2 and $2 \mathrm{~m} / \mathrm{s}, \mathrm{T}_{0}$ of $850 \mathrm{~K}$ and $1050 \mathrm{~K}$. It is found that twostage ignition plays an important role in PCCI engines if $\mathrm{T}_{0}$ is within the NTC regime. Increasing $\varphi^{\prime}$ has little impact on LTHR but the overall temperature gradient becomes larger such that HTHR advances and the peak decreases; Increasing $\mathrm{T}^{\prime}$ will lead to lower peak of LTHR and retarded secondstage ignition delay time. Stronger turbulence has little effect on ignition delay time for the current two-stage ignition fuel because the ignition delay time is very sensitive to equivalence ratio and temperature distribution. The effect of species diffusion is rather small considering the turbulence timescale is longer or on the same order of ignition delay time, such that the combustion is mainly controlled by chemical kinetics.

A series of 1-D DNS cases are simulated considering different initial temperatures: $850 \mathrm{~K}$ (within NTC regime), $1050 \mathrm{~K}$ and $781 \mathrm{~K}$ (outside of the NTC regime) and positive, negative and uncorrelated T- $\varphi$ distributions. The results show that, at the condition of positive $\mathrm{T}-\varphi$ correlation, there is no NTC phenomenon, while high temperature and high equivalence ratio region ignites first; at the condition of negative $T-\varphi$ correlation, the low temperature and high equivalence ratio region ignites first due to the NTC effect; at the condition of non-correlated $\mathrm{T}_{0}-\varphi$, a most reactive mixture is found and multiple ignition sites occur sequentially. Meanwhile, no matter whether $\mathrm{T}_{0}$ is within or outside the NTC regime, species diffusion effect is small compared with species reaction rate in the current cases.

\section{Acknowledgements}

The project is sponsored by the Scientific Research Foundation (SRF) for the Returned Overseas Chinese Scholars (ROCS), State Education Ministry (SEM) and also by the National Science Foundation of China (NSFC) No. 51320105008, No. 51406233. All the two dimensional DNS cases are 
performed on TianHe-1(A) system at National Supercomputer Center in Tianjin, China. Authors would like to thank Xuesong Bai from Lund University for revising this manuscript and polishing the language. 


\section{References}

[1] Kook S, Bae C, Kim J. Diesel-fuelled homogeneous charge compression ignition engine with optimized premixing strategies. Int. J. Eng. Res. 2007; 8: 127-37.

[2] Zheng Z, Liu C, Zhang X. Numerical study of effects of reformed exhaust gas recirculation (REGR) on dimethyl ether HCCI combustion, Int. J. Hydrogen Energy 2014, 39:8106-8117.

[3] Liu H.F., Yao M.F., Zhang B., Zheng Z., Influence of fuel and operating conditions on combustion characteristics of a homogeneous charge compression ignition engine, Energy Fuels 2009; 23: 1422-1430.

[4] Nishi M., Kanehara M., Iida N., Assessment for innovative combustion on HCCI engine by controlling EGR ratio and engine speed, Appl. Therm. Eng. 2016; 99: 42-60.

[5] Pipitone E., Genchi G., NOx reduction and efficiency improvements by means of the Double Fuel HCCI combustion of natural gas-gasoline mixtures, Appl. Therm. Eng. 2016; 102:10011010.

[6] Sharma P., Dhar A., Development of chemical kinetics based hydrogen HCCI combustion model for parametric investigation, Int. J. Hydrogen Energy 2016;41:6148-6154.

[7] Jia M, Li Y, Xie M., et al., Numerical evaluation of the potential of late intake valve closing strategy for diesel PCCI (premixed charge compression ignition) engine in a wide speed and load range, Energy 2013; 51:203-215.

[8] Jia, M., Xie, M., Wang, T., Peng, Z., The effect of injection timing and intake valve close timing on performance and emissions of diesel pcci engine with a full engine cycle cfd simulation, Appl. Energy 2011; 88: 2967-2975.

[9] Das P., Subbarao P.M.V., Subrahmanyam J.P., Control of combustion process in an HCCI-DI combustion engine using dual injection strategy with EGR, Fuel 2015; 159: 580-589.

[10] Dec J.E., Hwang W., Sjöberg M., An investigation of thermal stratification in HCCI engines using chemiluminescence imaging, SAE paper 2006-01-1518.

[11] Liu H.F., Zhang P., Li Z., Luo J., Zheng Z., Yao M., Effects of temperature inhomogeneities on the HCCI combustion in an optical engine, Appl. Therm. Eng. 2011; 31: 2549-2555. 
[12] Liu H.F., Zheng Z., Yao M.F., Zhang P., Zheng Z., He B., Qi Y., Influence of temperature and mixture stratification on HCCI combustion using chemiluminescence images and CFD analysis, Appl. Therm. Eng. 2012;33: 135-143.

[13] Hultqvist A., Christensen M., Johansson B., Richter M., Nygren J., Hult J., Alden M., The HCCI Combustion Process in a Single Cycle-High-Speed Fuel Tracer LIF and Chemiluminescence Imaging, SAE paper 2002-01-0424.

[14] Kook S., Park S., Bae C., Influence of early fuel injection timings on premixing and combustion in a diesel engine, Energy Fuel 2007; 22: 331-37.

[15] Kim K, Kim D, Jung Y, Bae C. Spray and combustion characteristics of gasoline and diesel in a direct injection compression ignition engine, Fuel 2013; 109: 616-26.

[16] Fang T, Coverdill RE, Lee CF, White RA. Effects of injection angles on combustion processes using multiple injection strategies in an HSDI diesel engine, Fuel 2008; 87: 3232-9.

[17] Fang T, Lee CF. Low sooting combustion of narrow-angle wall-guided sprays in an HSDI diesel engine with retarded injection timings, Fuel 2011; 90: 1449-56.

[18] Fang T.G., Coverdill R.E., Lee C.F., White R.A., Effect of the injection angle on liquid spray development in a high-speed direct-injection optical diesel engine, P I Mech. Eng. D-J Aut. 2009; 223: 1077-92.

[19] Su W.H., Yu W.B., Effects of mixing and chemical parameters on thermal efficiency in a partly premixed combustion diesel engine with near-zero emissions, Int. J. Eng. Res. 2012; 13: $188-98$.

[20] Hwang W., Dec J.E., Sjöberg M., Fuel Stratification for Low-Load HCCI Combustion: Performance \& Fuel-PLIF Measurements, SAE paper 2007-01-4130.

[21] Krisman A., Hawkes E.R., Kook S., Sjöberg M., Dec J.E., On the potential of ethanol fuel stratification to extend the high load limit in stratified-charge compression-ignition engines, Fuel 2012; 99: 45-54.

[22] Yu R., Bai X.S., Direct numerical simulation of lean hydrogen/air autoignition in a constant volume enclosure, Combust. Flame 2013; 160: 1706-1716. 
[23] Chen J.H., Hawkes E.R., Sankaran R., Mason S.D., Im H.G., DNS of ignition front propagation in a constant volume with temperature inhomogeneities I, Combust. Flame 2006; 145: 128-144.

[24] El-Asrag H. A., Ju Y., Direct numerical simulations of NOx effect on multistage autoignition of DME/air mixture in the negative temperature coefficient regime for stratified HCCI engine conditions, Combust. Flame 2014; 161; 256-269.

[25] Zhang H., Hawkes E.R., Chen J.H., Kook S., A numerical study of the autoignition of dimethyl ether with temperature inhomogeneities, Proc. Combust. Inst. 2013; 34: 803-812.

[26] Fukushima. N. Katayama M. Naka Y. et al., Combustion regime classification of HCCI/PCCI combustion using Lagrangian fluid particle tracking, Proc. Combust. Inst. 2015; 35: 30093017.

[27] Thirouard B., Cherel J., Knop V., Investigation of mixture quality effect on CAI combustion, SAE paper 2005-01-0141.

[28] Ju Y., Sun W., Burke M.P., Gou X., Chen Z., Multi-timescale modeling of ignition and flame regimes of n-heptane-air mixtures near spark assisted homogeneous charge compression ignition conditions, Proc. Combust. Inst. 2011; 33:1245-1251.

[29] Yoo C.S., Luo Z., Lu T., Kim H., Chen J.H., A DNS study of ignition characteristics of a lean iso-octane/air mixture under HCCI and SACI condition, Proc. Combust. Inst. 2013; 34: 29852993.

[30] Bansal G., Im H.G., Autoignition and front propagation in low temperature combustion engine environments, Combust. Flame 2011; 158: 2105-2112.

[31] Luong M.B., Yua G.H., Lu T., Chung S.H., Yoo C.S., Direct numerical simulations of ignition of a lean n-heptane/air mixture with temperature and composition inhomogeneities relevant to HCCI and SCCI combustion, Combust. Flame 2015; 000: 1-20.

[32] Tang Q., Zhang P., Liu H.F., Yao M., Measurements of Formaldehyde and OH Radical in Dual-fuel Combustion Process of Engine by Laser-induced Fluorescence, J. Chem. Phys. 2015; 31: 9 . 
[33] Kelly-Zion P.L., Dec J.E., A computational study of the effect of fuel type on ignition time in homogeneous charge compression ignition engines, Proc. Combust. Inst. 2000; 28: 1187-1194.

[34] Sjöberg M., Dec J.E., Smoothing HCCI heat-release rates using partial fuel stratification with two-stage ignition fuels, SAE paper 2006-01-0629.

[35] Tanaka S., Ayala F., Keck J.C., Heywood J.B., Two-stage ignition in HCCI combustion and HCCI control by fuels and additives, Combust. Flame 2003;132: 219-239.

[36] Tsurushima T., A new skeletal PRF kinetic model for HCCI combustion, Proc. Combust. Inst., 2009; 32: 2835-2841.

[37] Yu R., Yu J.F., Bai X.S., An improved high-order scheme for DNS of low Mach number turbulent reacting flows based on stiff chemistry solver, J. Comput. Phys. 2012;231:5504-5521.

[38] Strang G., On the construction and comparison of difference schemes, SIAM J. Numer. Anal. 1968;5:506-517.

[39] Zhang F., Yu R., Bai X.S., Direct numerical simulation of PRF70/air partially premixed combustion under IC engine conditions, Proc. Combust. Inst. 2014; 35: 2975-2982.

[40] Zhang F., Direct Numerical Simulations of Low Temperature Combustion in IC Engine Related Conditions, Ph.D. Thesis 2013, Lund University, Sweden, ISSN 0282-1990.

[41] Thirouard B., Cherel J., Knop V., Investigation of Mixture Quality Effect on CAI Combustion, SAE paper 2005-01-0141.

[42] Pera C., Chevillard S., Reveillonet J., Effects of residual burnt gas heterogeneity on early flame propagation and on cyclic variability in spark-ignited engines, Combust. Flame 2013; 160: 1020-1032.

[43] Passot T., Pouquet A., Numerical simulation of compressible homogeneous flows in the turbulent regimes, J. Fluid Mech. 1987; 118: 441-466.

[44] Yoo C.S., Lu T., Chen J.H., Law C.K., DNS of ignition of a lean-heptane/air mixture with temperature inhomogeneities at constant volume: Parametric study, Combust. Flame 2011; 158: $1727-1741$. 
[45] Mittal V., Cook D.J., Pitsch H., An extended multi-regime flamelet model for IC engines, Combust. Flame 2012; 159: 2767-2776.

[46] Kraichnan R.H., Diffusion by a random velocity field, Phys. Fluid 1970;13:22.

[47] Curran H.J., Gaffuri P., Pitz W.J., Westbrook C.K., A Comprehensive Modeling Study of nHeptane Oxidation, Combust. Flame 1998; 114:149-177.

[48] Talei M., Hawkes E. R., Ignition in compositionally and thermally stratified n-heptane/air mixtures: A direct numerical simulation study, Proc. Combust. Inst. 2015; 35: 3027-3035.

[49] Pope S.B., Turbulent Flows, (Cambridge University Press, Cambridge, UK, 2000).

[50] Mukhopadhyay S., Abraham J., Influence of compositional stratification on autoignition in nheptane/air mixtures, Combust. Flame 2011; 158: 1064-1075.

[51] Farouk T.I., Dryer F.L., Isolated n-heptane droplet combustion in microgravity: "Cool Flames"-Two-stage combustion, Combust. Flame 2014; 161: 565-581.

[52] Luong M.B., Luo Z.Y., Lu T.F., Chung S.H., Yoo C.S., Direct numerical simulations of the ignition of lean primary fuel/air mixtures with temperature inhomogeneities, Combust. Flame 2013; 160: 2038-2047. 
Table 1

Simulation cases and initial conditions

\begin{tabular}{ccccccc}
\hline Case & $R e$ & $u^{\prime}[\mathrm{m} / \mathrm{s}]$ & $T^{\prime}[\mathrm{K}]$ & $\mathrm{T}_{0}[\mathrm{~K}]$ & $\varphi^{\prime}$ & $\eta[\mu \mathrm{m}]$ \\
\hline 1 & 73 & 0.2 & 15 & 850 & 0.03 & 12.3 \\
2 & 73 & 0.2 & 15 & 850 & 0.3 & 12.3 \\
3 & 730 & 2 & 15 & 850 & 0.03 & 3.2 \\
4 & 73 & 0.2 & 30 & 850 & 0.03 & 12.3 \\
5 & 73 & 0.2 & 15 & 1050 & 0.3 & 12.3 \\
\hline
\end{tabular}


FIGURE 1

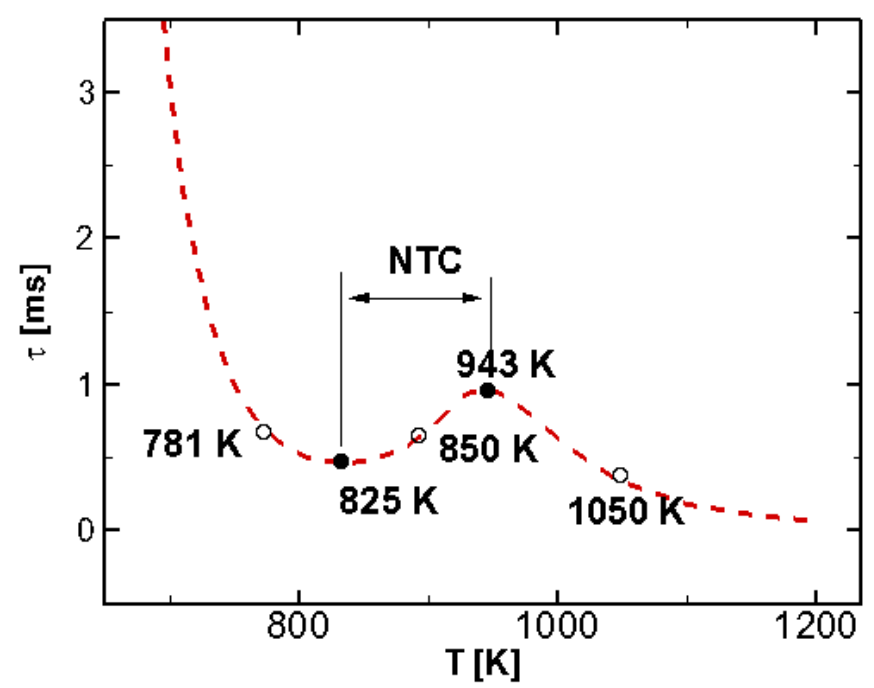

a)

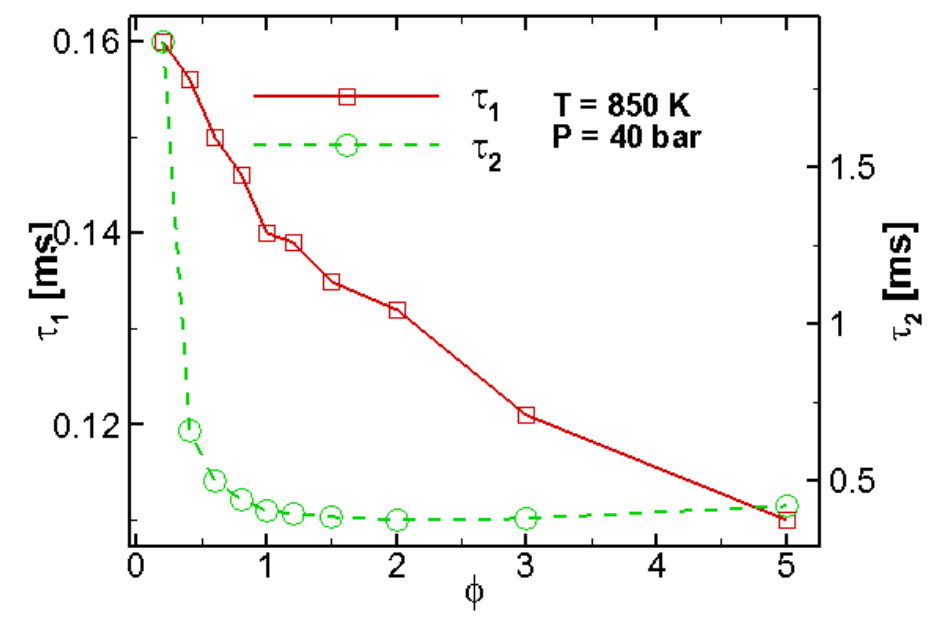

b) 
FIGURE 2

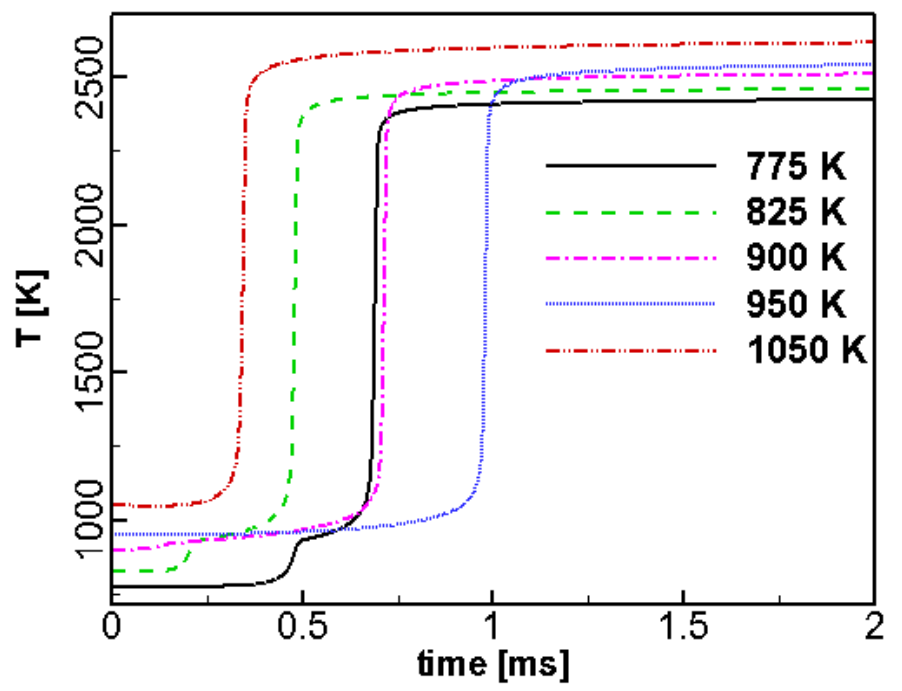

a)

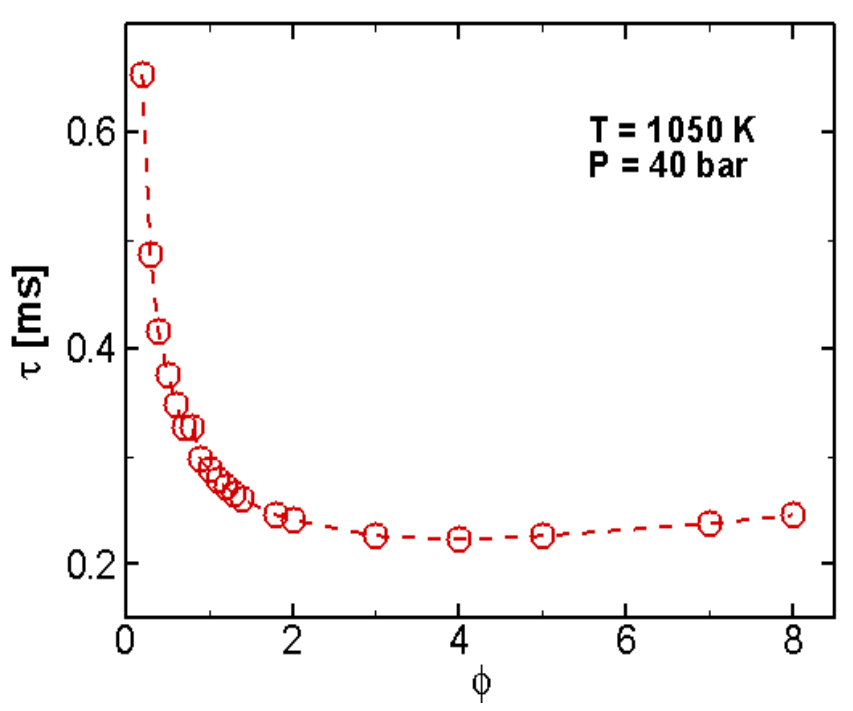

b) 
FIGURE 3

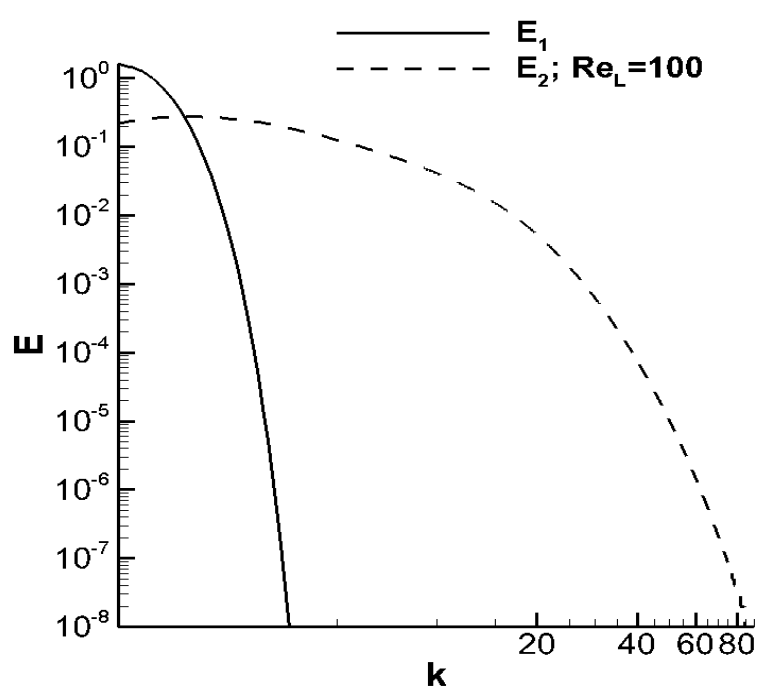

a)

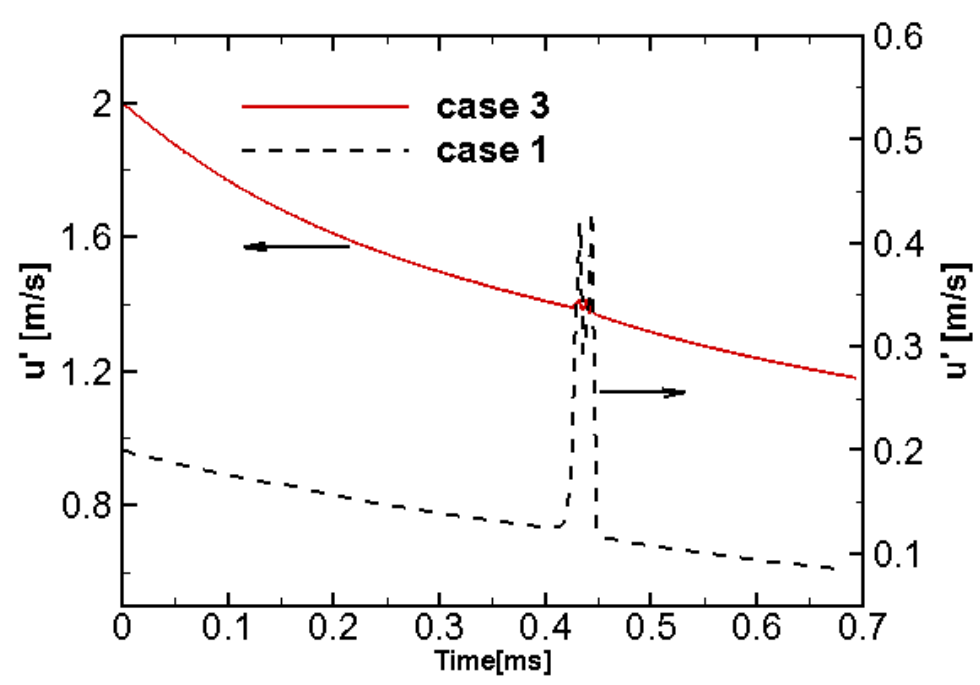

b) 
FIGURE 4

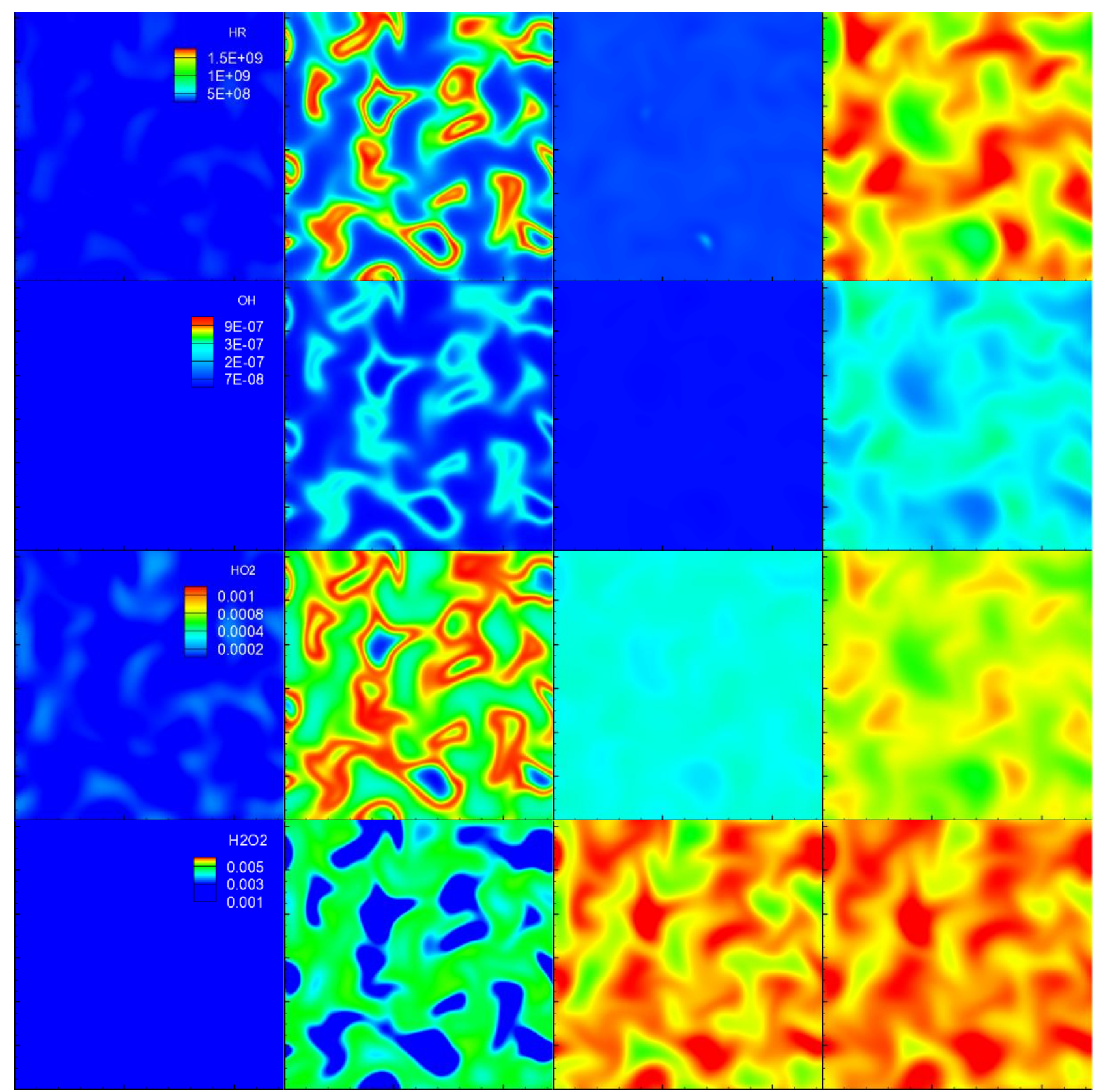


FIGURE 5

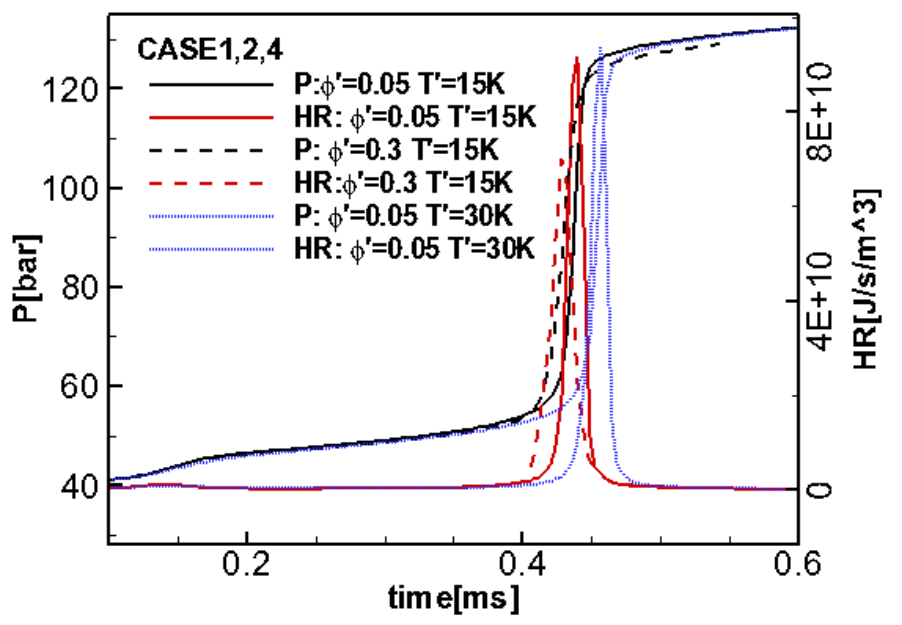

a)

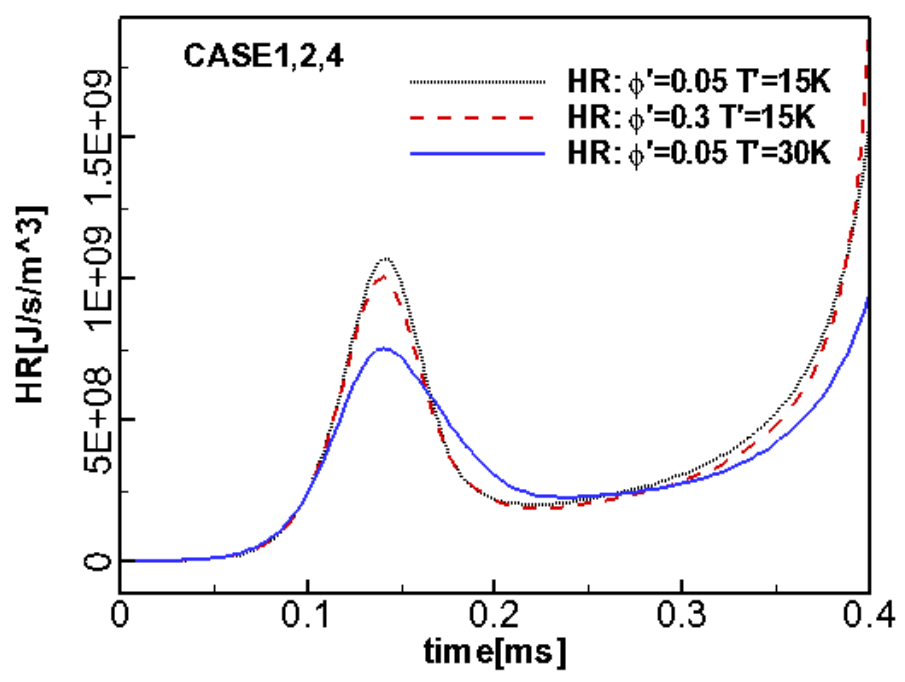

b) 
FIGURE 6

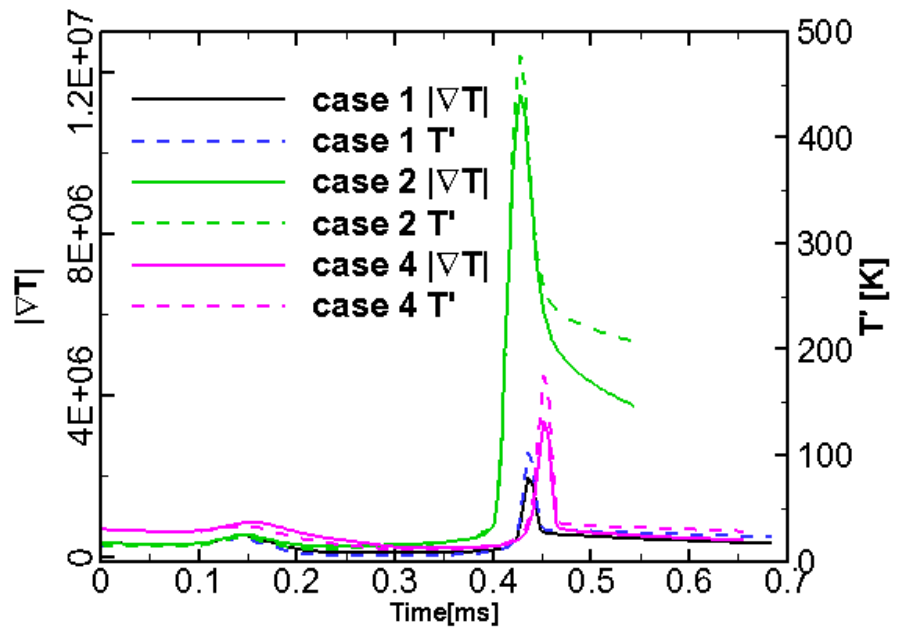


FIGURE 7

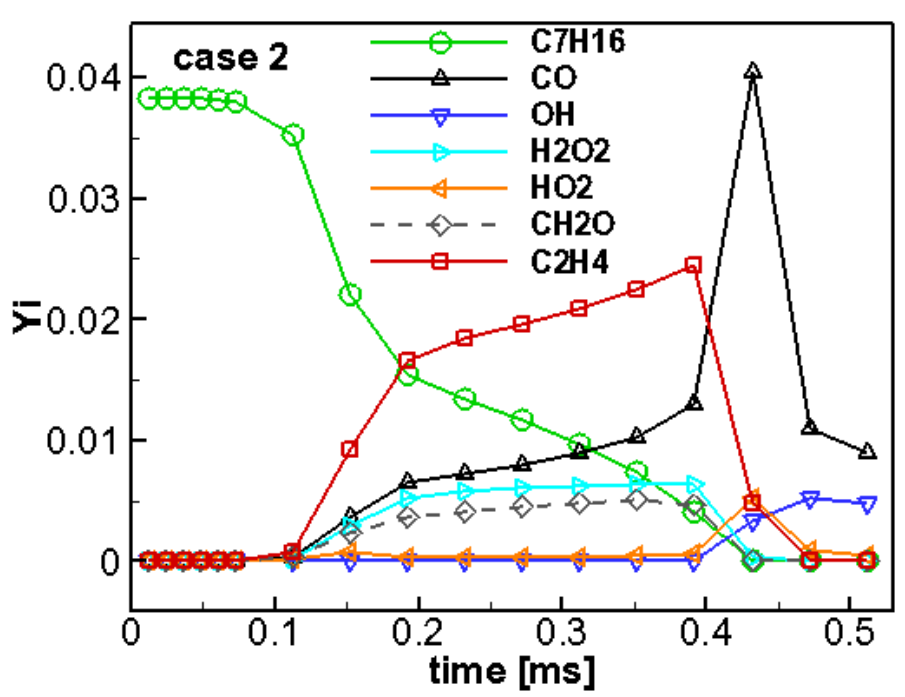

a)

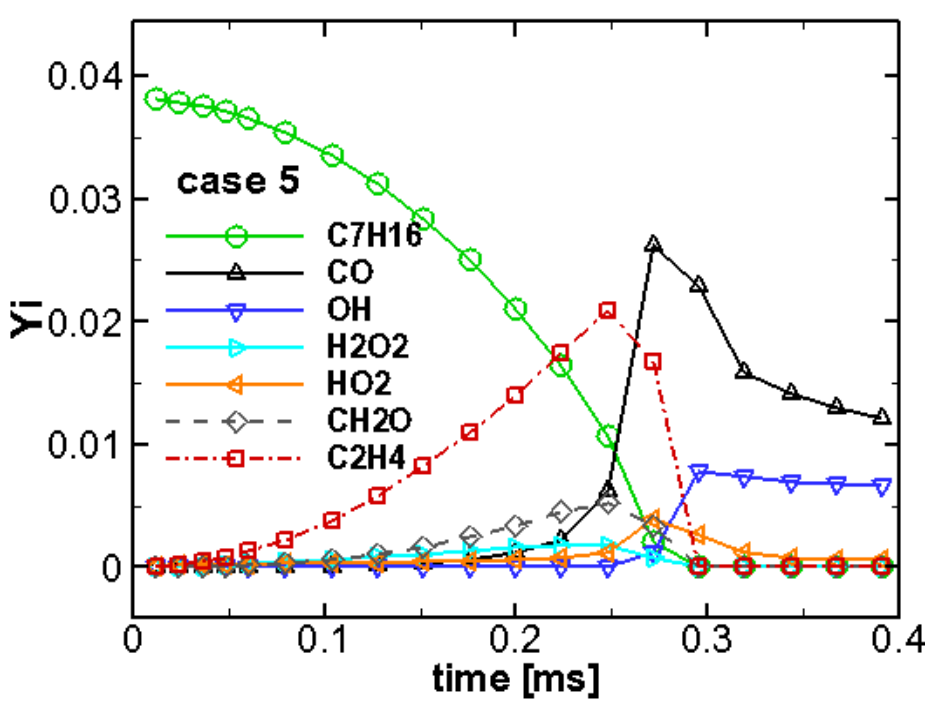

b) 
FIGURE 8

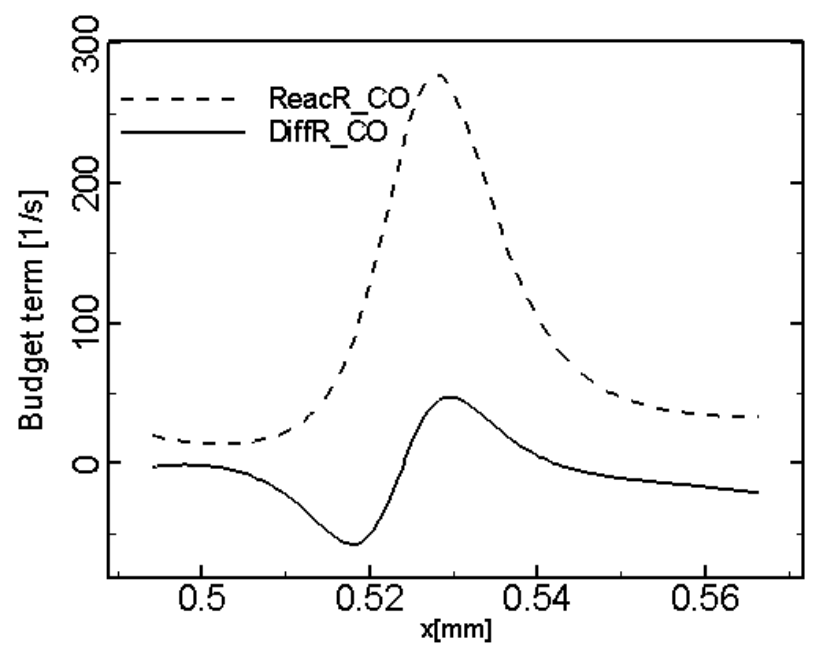

a)

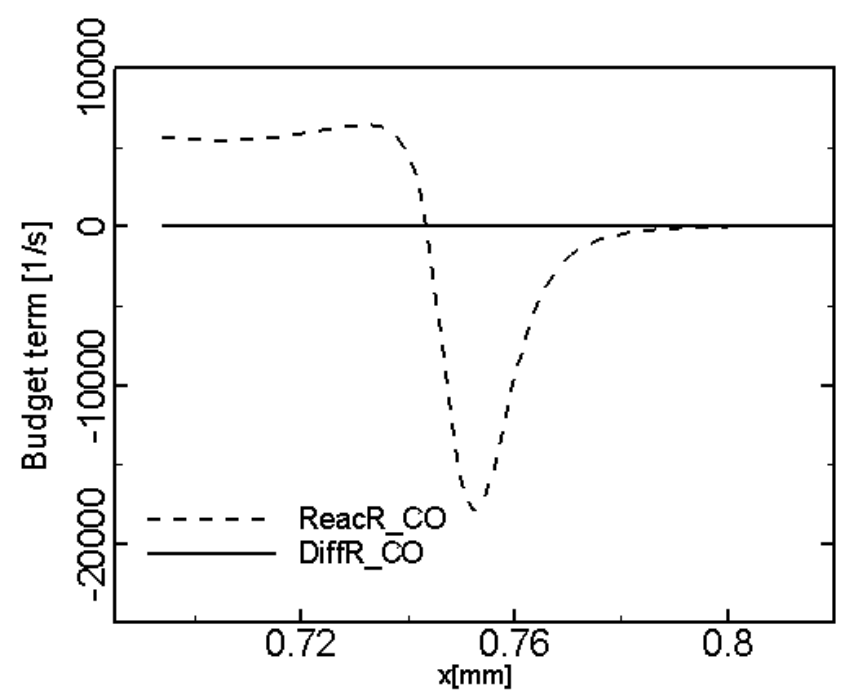

b) 
FIGURE 9

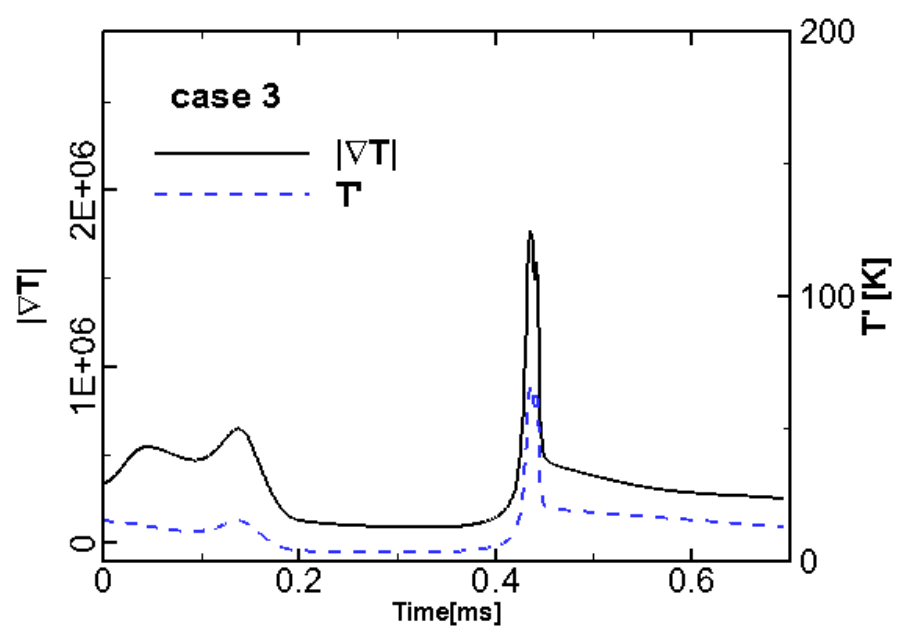

(a) 
FIGURE 10

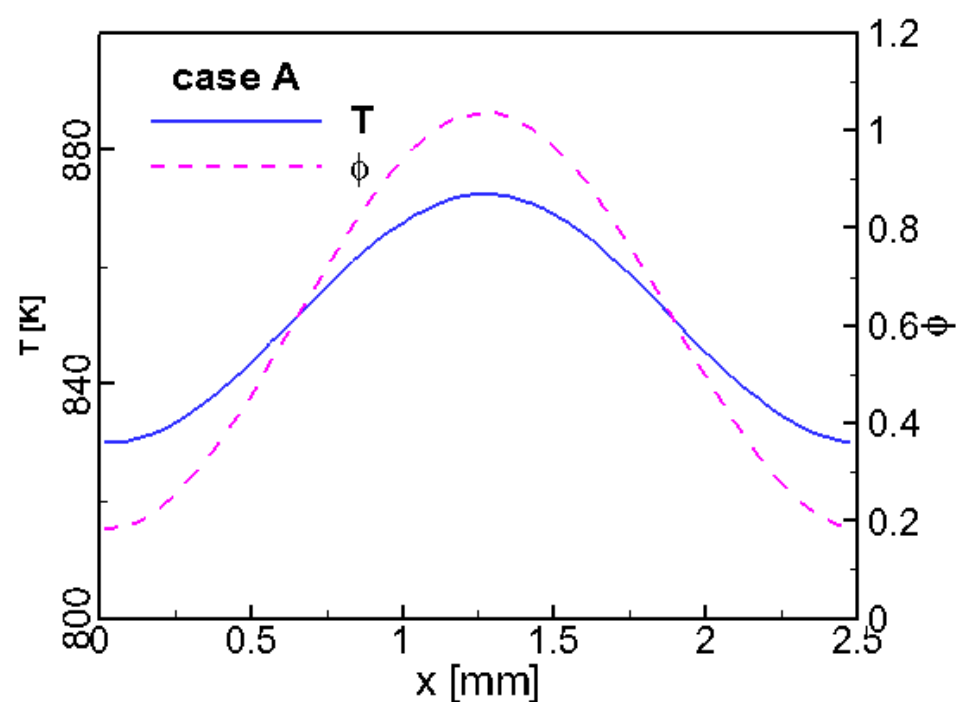

a)

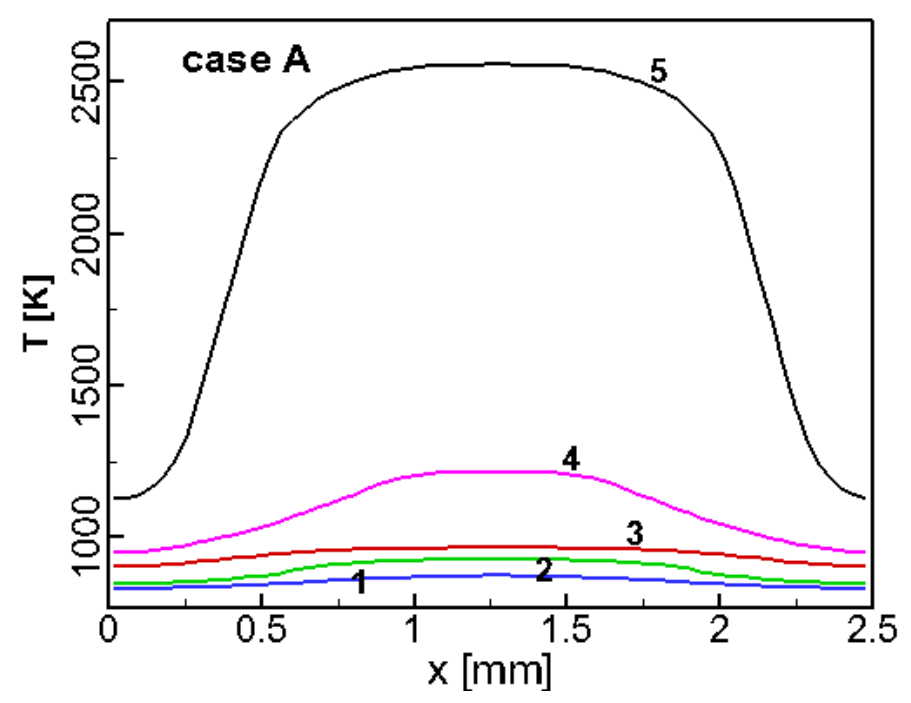

b) 
FIGURE 11

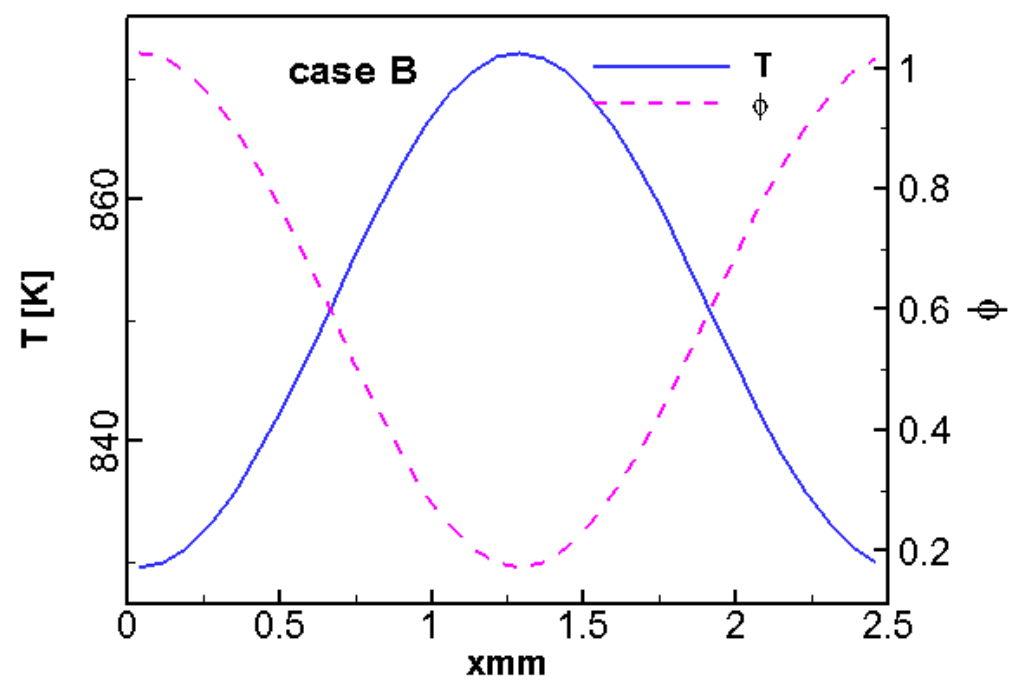

a)

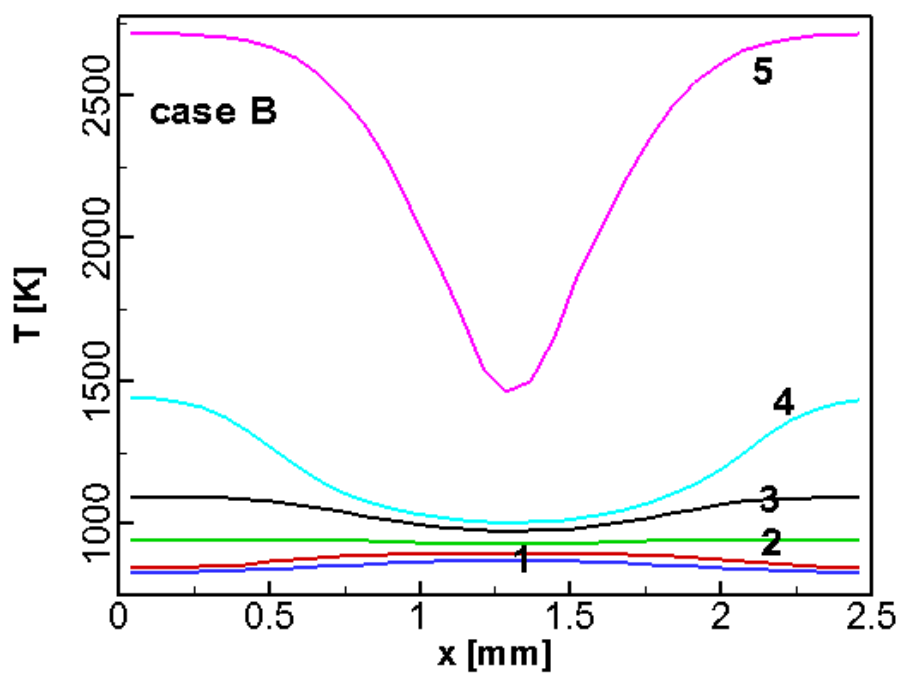

b) 
FIGURE 12

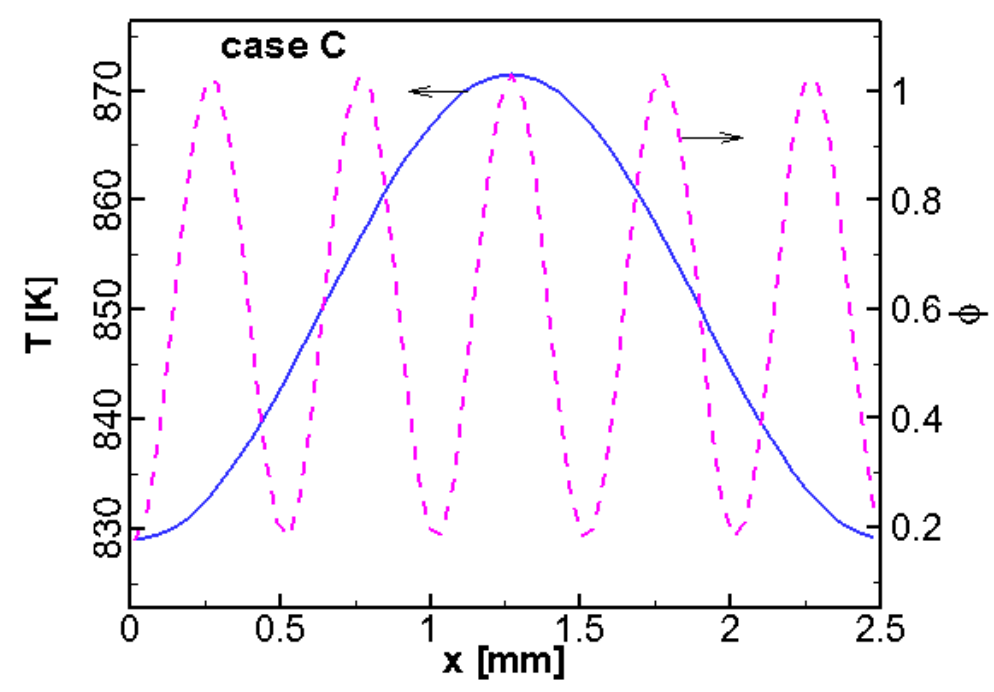

a)

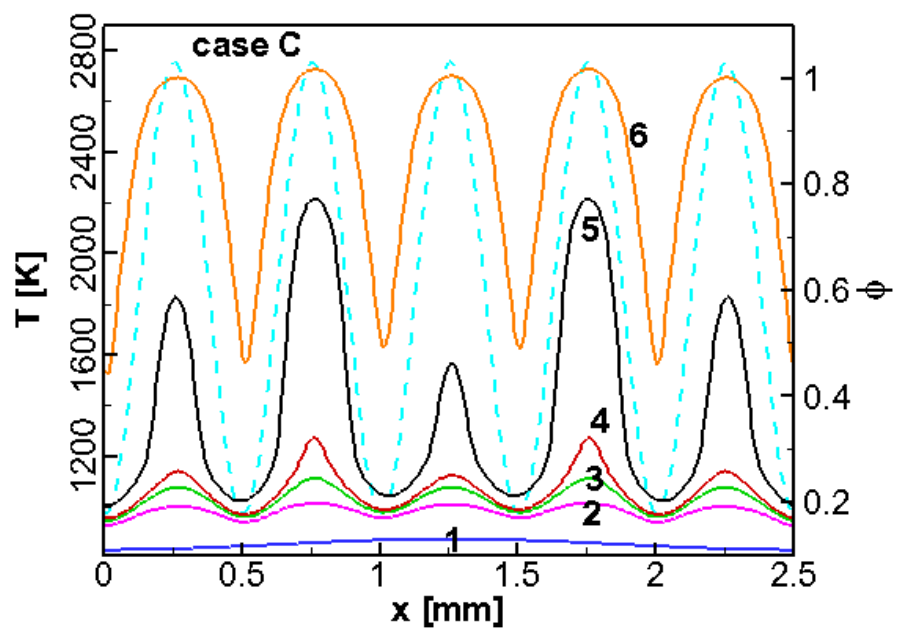

b) 
FIGURE 13

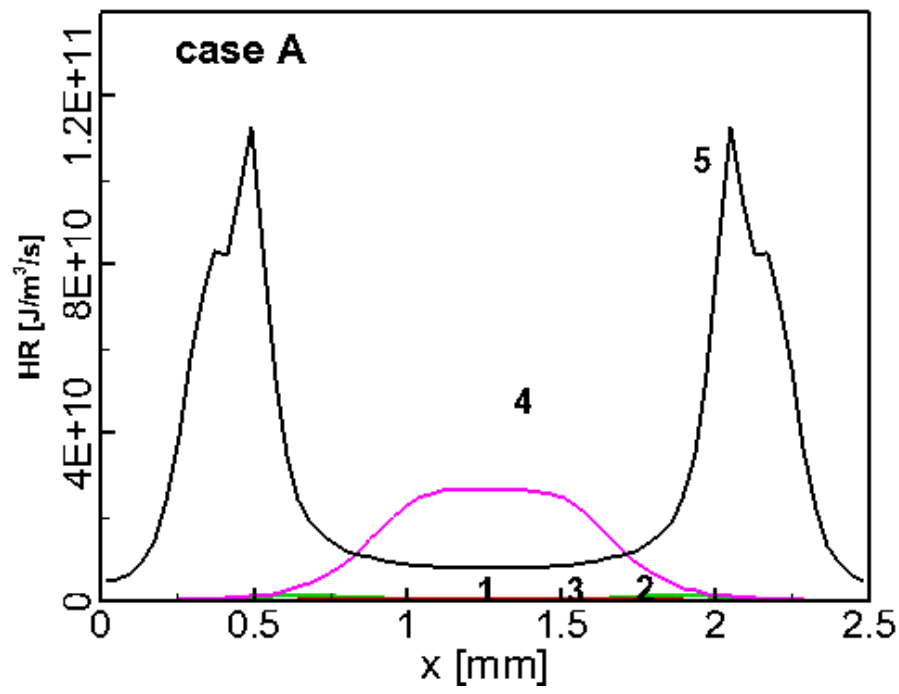

a)

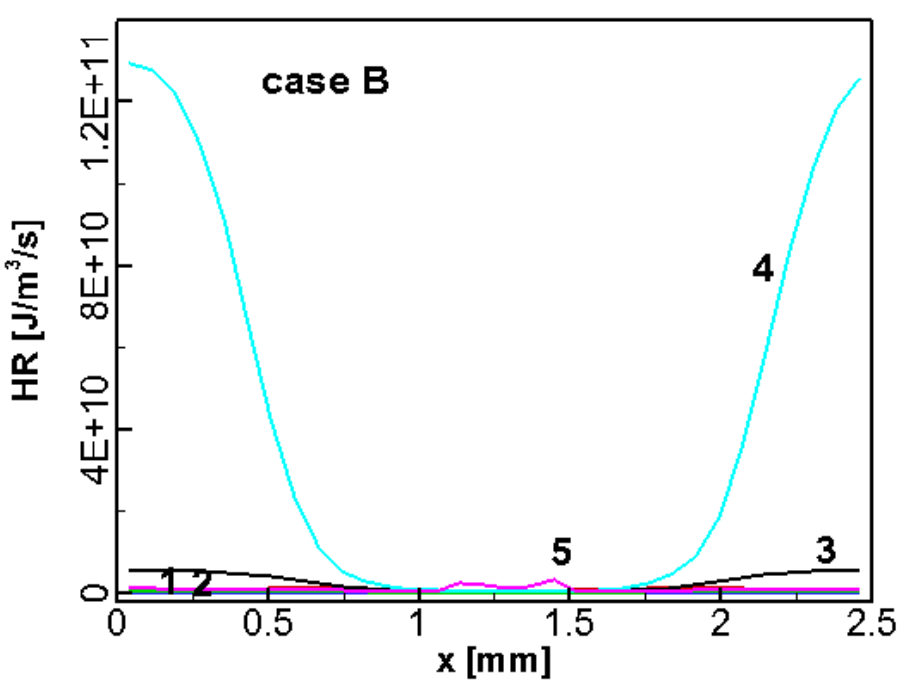

b)

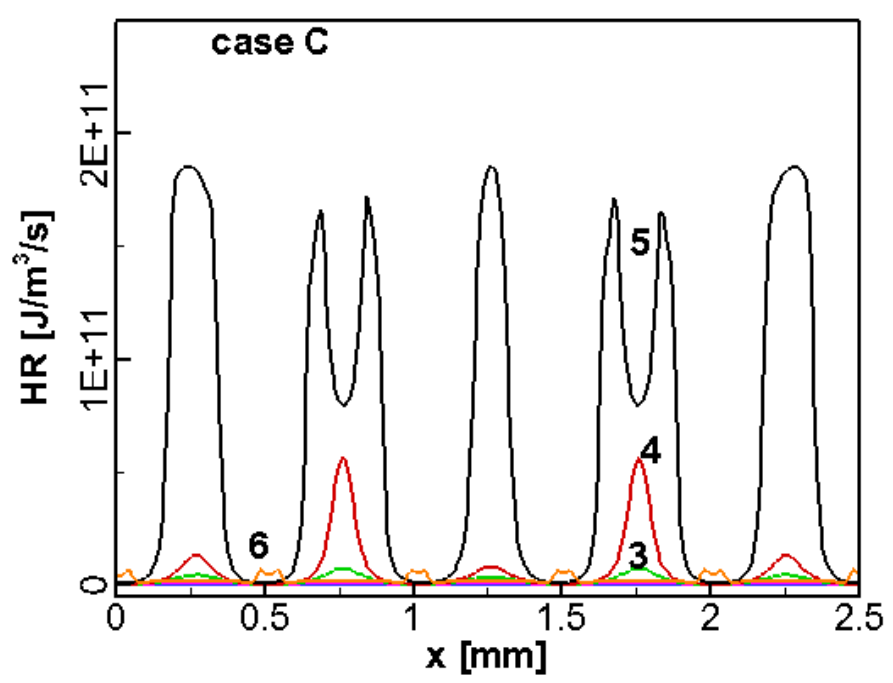

c) 
FIGURE 14

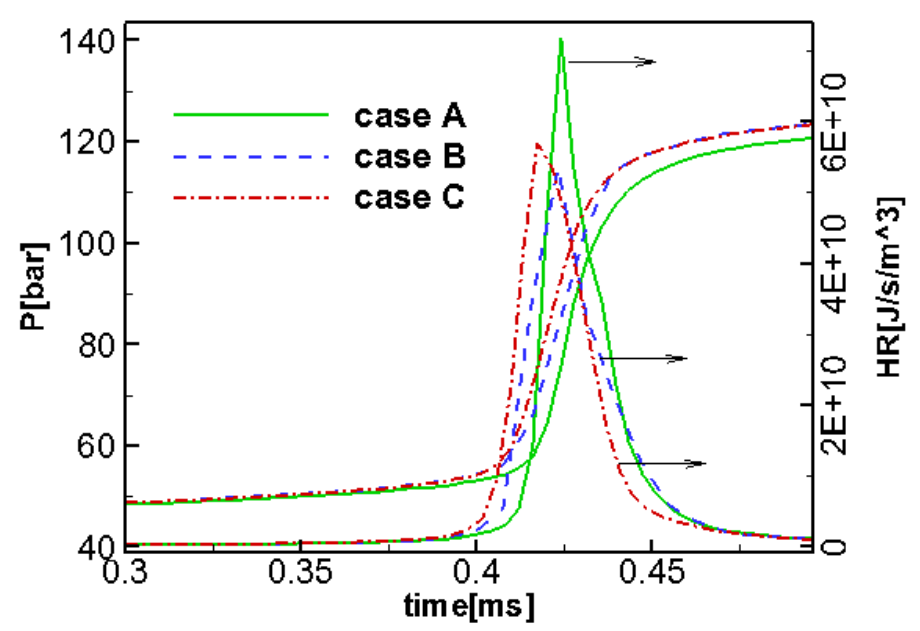

a)

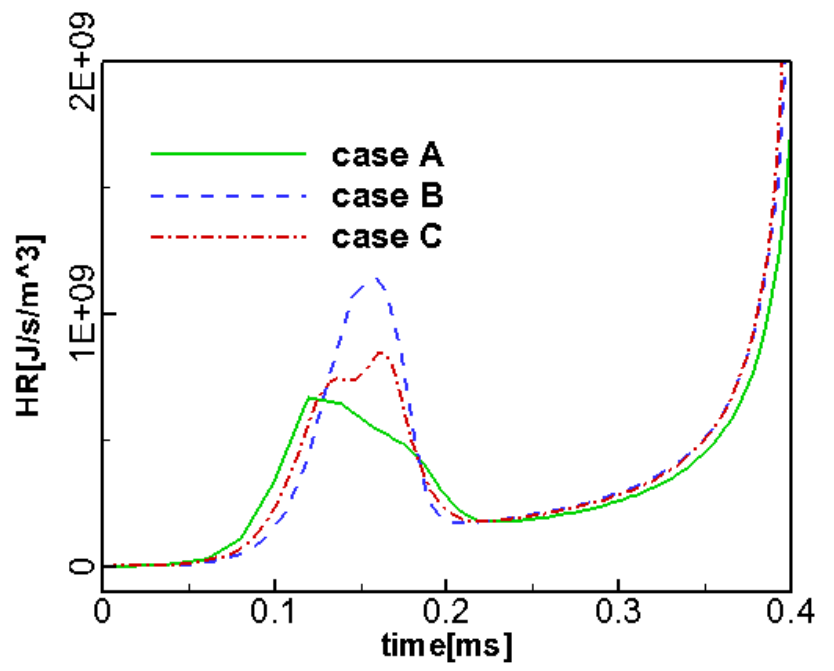

b) 


\section{FIGURE CAPTION}

Fig. 1 a) Homogeneous ignition delay time as a function of initial temperature; b) the first and second homogeneous ignition delay time as a function of equivalence ratio

Fig. 2 a) Temporal evolution of temperature profiles under different initial conditions; b) ignition delay time as a function of equivalence ratio

Fig. 3 a) energy spectra as a function of wave number; b) temporal evolution of turbulent velocity in cases 1 and 3

Fig. 4 2-D distribution of $\mathrm{HR}, \mathrm{OH}, \mathrm{HO}_{2}$ and $\mathrm{H}_{2} \mathrm{O}_{2}$ mass fraction at four time instants (from left to right: $0.089 \mathrm{~ms}, 0.16 \mathrm{~ms}, 0.28 \mathrm{~ms}$ and $0.4 \mathrm{~ms}$ ) for case 1 . The domain length is $1.2 \mathrm{~mm}$.

Fig. 5 a) Temporal evolution of pressure and volume averaged total heat release rate for cases 1, 2 and 4 ; b) time history of volume averaged total LTHR for cases 1, 2 and 4.

Fig. 6 Temporal evolution of the volume-averaged temperature gradient and fluctuation

Fig. 7 Temporal evolution of fuel and main species mass fractions for a) case 2 and b) case 5

Fig. 8 Budget terms of CO on the reaction front at a) LTHR $(0.16 \mathrm{~ms})$ and b) HTHR $(0.41 \mathrm{~ms})$ stages

Fig. 9 Temporal evolution of temperature gradient and fluctuation in case 3

Fig. 10 a)Initial T- $\varphi$ distribution with positive correlation; b)T distribution at five time instants in 1D case A 
Fig. 11 a) Initial $\mathrm{T}-\varphi$ distribution with negative correlation; b) T distribution at five time instants in $1-\mathrm{D}$ case $\mathrm{B}$

Fig. 12 a) Initial uncorrelated T- $\varphi$ distribution; b) $\mathrm{T}$ distribution at five time instants in 1-D case C, the dashed line represents $\varphi$

Fig. 13 a)-c) Temporal evolution of heat release rate for 1-D cases A-C, respectively

Fig. 14 Temporal evolution of a)HTHR and b)LTHR for 1-D cases A-C 